\title{
Corporate Social Responsibility, Problems, Behaviour, and change in financial firms.
}

\author{
John Holland, \\ The Adam Smith Business School, University of Glasgow, Main Building, Glasgow, G12 8QQ, Scotland, UK
}

\begin{abstract}
The research question is How can financial firms become corporate socially responsible (CSR)? Changes in financial firms and financial markets to become CSR oriented are being driven by global physical changes, intensive world-wide political and institutional pressures, and increasingly critical and demanding employees, customers, and civil society stakeholders (Dashwood, 2020).

The change pressures combine with problematic internal firm predispositions (in knowledge, values, beliefs, organisation, behaviour etc) to exacerbate barriers to change and contribute to CSR problems, both historic and emerging.

Empirical research into CSR problems in financial firms, and the wider debate about CSR change, reveals four themes. These are portrayed as four metaphors (Morgan, 1997) concerning: 'Head' (top teams), 'House' (socio-technical system), 'Community' (lived experience of employees, customers, and stakeholders), and decision making in a financial 'Machine'. These elements form a connected, interacting, changing system reflecting Hirshleifer's (2015) argument that there is a need to move from behavioural finance to social finance. CSR problems and demands for CSR change arise in each metaphor area and predispositions, and their dynamic interactions in firms and externally. These contribute to problems of CSR communication and reporting. This CSR empirical change narrative and metaphor elements are interpreted using literature and theory relevant to the whole system and each metaphor. This interdisciplinary analysis (de Bakker et al, 2019) is used to develop an equivalent theoretical narrative. The combined narratives form a CSR oriented 'Behavioural theory of the financial firm' (CSR BTTF).
\end{abstract}

This conceptual framework is used to explore CSR problems in financial firms. It is means to think how to - manage and research CSR change problems and become fully CSR oriented. This knowledge strategy (Zack, 1999), by closing knowledge and value gaps within the firm and externally, in both practice and academic domains, directly addresses issues of uncertainty and complexity arising from CSR change. It is part of the evolving means to realign value in financial markets with values of wider society (Carney, 2020).

The enhanced empirical and theory understanding in the CSR BTFF supports development of an academic research programme about 'CSR Finance' using a range of non-finance academic disciplines. The CSR BTFF is also a basis to develop firm-wide hypotheses for empirical tests in CSR finance (Poterba, 2021) and test for 'CSRwash' (Pope et al, 2016). It can encourage a rethink of research and theory development in finance (Gendron, \& Smith-Lacroix, 2013 Holland, 2019a). It contributes to developing holistic and integrated CSR communication and reporting.

Thus, this holistic narrative and metaphor approach is a means to answer the question, 'What is going on here?' and to be able to 'stand back' and comprehend the bigger picture and central strategic issues when responding to uncertainty (p10, p528, Kay and King, 2020). The four-part metaphors and narrative break down the complex problems and aid comprehension of the whole system. Individual metaphors provide insights into each major part of the system and focusses attention on critical change factors. This approach has potential 'to make a difference' in; researching, learning, thinking, and believing about desirable actions and responses to CSR problems and to demands for CSR oriented change in financial firms and wider systems (Shiller, 2019).

\section{Outline of paper}

Section 1 discusses the motivation for the paper and approach adopted. It notes increasing demands for CSR change in values, knowledge, behaviour, and outcomes in financial firms. These arise from changes in physical and human systems, both global and national. These combine with problematic internal predispositions in a complex financial firm system. In these conditions, cases occur where top teams and employees cannot, or do not wish to, adjust fast enough to external CSR change pressures, and CSR problems arise in financial firms and external networks. The paper argues that CSR change, CSR problems and associated problems of knowledge and 'values' can be in part ameliorated by developing an enhanced holistic understanding of financial firms and by improved transparency about financial firms and CSR.

Section 2 outlines use of qualitative methods to understand: the 'soft' infrastructure of financial firms; its role in operational activities and financial decisions; and how these are means to reduce CSR problems and manage CSR change. This section discusses theoretical interpretation of empirical insights, and use of metaphor to succinctly communicate insights, as the basis to develop a holistic conceptual framework to respond to CSR change. This involves developing a firm-wide hypothesis (Poterba, 2021) about CSR change in the financial firm. This takes the form of a CSR oriented 'behavioural theory of the financial firm' (CSR BTFF).

Section 3 briefly outlines how financial firms can become corporate socially responsible (CSR) in a more systemic way. This involves using the CSR BTFF to develop integrated thinking and action (VRF, 2021). In the CSR BTFF the 
firm consists of connected empirical themes or metaphors (Morgan, 1997) of 'Head', 'House', 'Community', and financial 'Machine'. These are based on historic and current CSR problems facing financial firms, interpreted in an interdisciplinary frame. The CSR BTFF is based on empirical and theoretical narratives (Golden-Biddle and Locke, 2007).

Section 4 uses the CSR BTTF to succinctly summarise and connect the main CSR problems (historic and current), arising in financial firms. CSR problems arise in key parts of financial firms such as the 'Head', 'House', 'Community', and financial 'Machine'. The CSR BTTF provides a new structure to recognise and understand CRS problems in each part and in their connections and interactions. This highlights problems how the firm can avoid problems and adapt in systematic way relative to external CSR change pressures.

Section 5 uses a change narrative to discuss how to change CSR behaviour in financial firms, in a systematic and holistic way at all levels. This uses the CSR BTTF to succinctly summarise CSR change processes in each area and interactions. It notes how CSR change can be managed in key parts of financial firms such as the 'Head', 'House', 'Community', and financial 'Machine' and during activities and interactions between these elements. This provides a new holistic structure to recognise and understand the CRS change process. This can reduce the likelihood of CSR change problems occurring in each area and across the whole firm system and external networks. This analysis provides new insights into how CSR reporting on change can be critically appraised and improved by financial firms.

Section 6 argues that the CSR BTFF capability for integrated thinking is the basis to support CSR oriented changes to the 'Head', 'House', 'Community' and Financial 'Machine, and steer the firm towards desired CSR and financial outcomes. Change in each of these core elements, and combined changes are intended to have a material impact on the outcomes. These CSR BTFF based narratives and ideas from the Integrated reporting framework (IIRC, 2013; VRF 2021) form a basis to develop value creation and CSR reporting content for integrated reports or $<$ IRs $>$. Section 7 summarises the paper and argues the CSR BTFF and enhanced 'integrated thinking' can be used to develop coherent and integrated approach to understanding CSR issues in the financial firm and to make a difference in key areas of CSR change.

\section{Introduction}

The research question of the paper is How can financial firms become CSR oriented? This section discusses the rationale for the research question, and motivation for paper and approach adopted. The primary focus is on the financial firm. However, the paper argues that significant CSR oriented change problems arise from combination of external change and internal barriers in financial firms. It initially explores external change contexts, and their contribution to CSR problems in financial firms.

Changes in external systems combine with problematic internal firm predispositions in knowledge, values, purpose, and social and economic organisation, to contribute to CSR oriented problems both historic and current. The paper argues an integrated response is required to subsequent knowledge and values gaps and associated CSR change problems. The paper discusses how these problems in the firm can be addressed in a holistic way. This provides insights how financial firms can become CSR oriented throughout the firm and, in part, resolve problems.

As a result, the research question is placed in the larger change context of changes in external physical systems (global economy, climate, human systems etc), associated change in world politics and activism, as well as changes in the world of finance. The research question and need for integrated thinking throughout the firm are directly addressed by developing a conceptual frame in the form of CSR oriented 'Behavioural theory of the financial firm'. The CSR BTFF develops an integrated narrative how intangibles at the 'Head' and 'House' in firms provide the purpose, structure, and resources to support the 'Community' of employees, to deliver CSR and financial outcomes in a financial 'Machine'. 
This is part of means required to reduce, in part, knowledge and values gaps in practice and academe in complementary ways, manage existing CSR problems, and improve responses to CSR change pressures and unexpected events.

The wider systems context

The paper notes increasing external demands for CSR change in financial firms. In this paper the external world is broadly characterised as a set of connected systems. These include physical systems such as the global economy, climate, and human settlements. They involve a wide range of connected human social systems affected by changes in physical systems. The financial firm is embedded in these larger external systems and forms the primary unit of analysis in the paper. Given complexity the paper briefly summarises the wider systems context to focus attention on specific external forces driving CSR change in the financial firm. This is essential to understand how financial firms can change individually and contribute to CSR change in larger systems.

The human systems include political, legal, business and finance community, and market systems, at global and national levels (Puxty et al, 1987; Whitley, 1999). The complex combinations of human systems are deeply connected forms of social order or institutional structure (Scott, 2001). They are forms of national and international political and economic order. They include global political processes at UN, EU, national level and with non-state actors, activists, and other stakeholders. They concern collaborative self-regulatory activities (Streeck, \& Schmitter, 1985) in Business and Finance Communities (systems), and socio-economic processes within individual financial firms and their markets. The wider system change context

These elements form different but connected systems, with shared risks and common change pressures. Each system interacts with other systems through direct influence and feedback mechanisms (Mumford, 2000). The wider global and national institutional settings form templates for the evolution towards new CSR oriented social order and for legitimising new CSR oriented behaviour. Physical changes, political pressures and CSR social norm changes also stimulate change in these wider social settings (Dashwood, 2020; Falkner, 2021).

These social structures are important influences on the behaviour of individuals and teams in financial firms. As a result, the financial firm is directly influenced by CSR change in each physical and human system and by their dynamic interactions. These contribute to CSR problems at the level of the firm.

More specifically, CSR change demands and problems have their roots in human actions and in physical changes such as globalisation, growth of world economy, technology, climate change, reduced biodiversity, Covid-19, and their impact on human systems. For example, global economic growth and changes (global supply chain, production, marketing, mass consumption) in the post 1970 period, have had major impact on climate change and biodiversity, and on humans and their social systems operating in this global economic system. These negative system interactions have contributed to CSR issues for employees, customers, activists, and other stakeholders. CSR change also arises from historic CSR problems and scandals in firms, and the impact of the GFC on financial firms(Holland, 2010). These contribute to global society wide perception of significant problems with CSR in businesses including financial firms.

Learning about this has promoted political processes and activism on CSR involving the UN, G20/G7, major regional blocs such as the EU, developed and developing countries, and non-state bodies such as the OECD, ILO, ISO, and CERES and its GRI. It involves companies, NGOs, CSOs, as well as increasingly critical and demanding civil society stakeholders.

This CSR oriented political processes has promoted acceptance of CSR norms in global society (Dashwood, 2020). They have also promoted acceptance of closely associated climate sustainability norms (Falkner, 2021). These 
complement each other in influencing CSR and green change at global levels. These changes in norms play a role in adapting the wider institutional setting.

However, aspects of the CSR debate remain contested (Dashwood, 2020; Kinderman, 2018). Tensions continue to exist between these norms, and nations ideas of sovereignty and nationalism. At business and finance community levels, tensions arise between, CSR norms and green norms, and belief in the role of markets and dominance of finance values. Belchambers (2021) also noted that many practitioners raise issues of collaboration. They face incomplete attempts by intergovernmental bodies, governments, regulators., financial firms, companies, and others to create a widely understood framework for collective CSR change. He argued that all parties recognised their shared complexity but faced problems of co-ordination and different world views, ideologies, goals, cultures, and professional roles. These problems at world and finance community levels, impact on problems at financial firm levels.

Despite contested aspect of the debate, the CSR changes are intended to have a positive feedback impact on physical and social systems and CSR outcomes. These social norms, and ongoing physical changes and political processes, play a role in driving change in economies and finance to protect human and physical systems from harm. They empower a community of increasingly critical and demanding employees, customers, activists, and civil society stakeholders. Participants in all four interacting systems are formally committed to reform business and finance for desirable CSR outcomes for employees, customers, activists, and other stakeholders. They play a role in increasing world-wide institutional and civil society demands for CSR change in understanding, values, behaviour, and outcomes in international businesses including financial firms.

Despite the problematic nature of world politics, and contested nature of CSR (Dashwood, 2020), progress is being made at this level. The global CSR norms are reflected in new global CSR standards. Kinderman (2018) notes these include the UN Global Compact (UN, 2021), the UN Guiding Principles on Business and Human Rights, the Global Reporting Initiative and the Carbon Disclosure Project. Intergovernmental actions also include the development of the UN SDGs (UNDP, 2016), and UN (UNIDO, 2019) and EU attempts to define CSR. For example, the European Commission defined Corporate Social Responsibility (EU, 2011) as

\footnotetext{
"the responsibility of enterprises for their impacts on society". "Respect for applicable legislation, and for collective agreements between social partners, is a prerequisite for meeting that responsibility. To fully meet their corporate social responsibility, enterprises should have in place a process to integrate social, environmental, ethical, human rights and consumer concerns into their business operations and core strategy in close collaboration with their stakeholders, with the aim of: -maximising the creation of shared value for their owners/shareholders and for their other stakeholders and society at large; -identifying, preventing and mitigating their possible adverse impacts".
}

\section{Changes in the finance community}

The above global and national changes also collectively drive CSR oriented changes in the finance community consisting of actors such as finance professional bodies, alliances of leading financial firms, non-state actors, activists, and other stakeholders. This promotes collaborative CSR change by alliances of connected financial firms. These alliances are self-regulating forms of social order (Streeck and Schmitter, 1985) that can increase the strategic alternatives for the solution of public policy problems.

For example, they develop specialist finance sector principles and guidance for CSR. These include 'Principles of Responsible Banking (PRB) (UNEP, 2018); and to professional standards set by bodies such as Chartered Banking Institute (CBI) (Bogan, 2018). They include PRI (2020) for fund managers and PSI for insurance firms (PSI, UNEP, 2012). Collaboration is also reflected in major finance community wide initiatives about ethics and greening of finance. For example, the development of the 'Ethical Finance' debate and idea and its promotion by Ethical Finance conferences, $(2020,2021)$ has created a way of framing for thinking about CSR change in finance. The Green Finance Summit (London 2018, 2019, 2020, 2021) and Business Green conferences have also stimulated change. 
The debate and collaboration in finance communities, has promoted finance community wide knowledge of 'good' CSR. This has been guided by the debate in international and national politics. This progress includes, inter alia, taxonomy of terms, outline of what CSR products are, and definitions of acceptable CSR behaviours and practices suitable for their member firms. It identifies what shared and agreed activities and practice can support high quality CSR outcomes for stakeholders such employees, customers, shareholders, and CSOs. This creates a 'level playing field' and defines 'rules of the game' for 'players' as individuals and teams in financial firm and network fields (Bourdieu, 1990). These finance community activities provide guidance for CSR change in individual financial firms operating in financial markets. These influential financial sector alliances expect significant CSR change in individual financial firms.

\section{Overall view of systems changes and outcomes}

The above illustrates attempts in global and finance community activities to develop a body of shared knowledge and values about CSR change. This reinforces learning from historic CSR problems, scandals and the GFC (Holland, 2010; Carnevale et al. 2012; Lock \& Seele, 2015). This highlights the significant role of the financial service industry and its CSR problems on society (Scholtens, 2009) and the need to respond to these issues

The external CSR change pressures from global politics and the finance community, also interact and combine with rapid change in the financial system and markets such as securitisation and Fintech, the impact of Covid-19, and with ongoing pressures for firms to improve financial performance. This creates a complex and rapidly changing external setting for individual financial firms.

Thus, CSR change involves interactions and influences at global physical level, political level, finance community, and financial firm levels. Participants in all systems are all involved in learning and adaption, revealing the wider dynamics at play here. Despite some contested aspects of CSR, participants in four interacting systems broadly wish to ameliorate the negative consequences of the complex changes for humans and their social and economic conditions, and for climate and biodiversity. They seek to ameliorate the consequences of failures in corporate social responsibility (CSR) for employees, customers, and stakeholders in a range of connected economic and social contexts.

Hence, momentum for co-ordinated CSR change is growing in all human systems to create positive impact on globalisation of economies, global business and finance, climate change and biodiversity concerns, and their impact on human activities and experiences. External changes and calls for CSR reform in connected and interacting physical, political, and finance community systems stimulate CSR change in systems and financial firms. Thus, these interacting systems set the wider context for this paper and its research question on how financial firms can adapt to CSR change.

However, the paper notes growing scepticism that such CSR oriented change in the wider external systems, proposed by supranational bodies such as the UN and EU (UN SDGs, 2016; EU, 2011), and in the business and finance community (eg GFANZ, 2021), will be effective in achieving CSR aims especially in reducing harm to human and physical systems. There is continuing scepticism that key financial firms such as banks will use these external changes for 'CSRwashing' purposes (Herold et al 2021; Norberg, 2018).

\section{External and internal sources of problems at financial firm level}

This external change situation is creating significant CSR problems and risks in financial firms. The external change pressures combine with problematic internal predispositions or change barriers to add to problems (Holland, 2010). The predispositions concern knowledge and values gaps - both as initial conditions, and as outcomes of the impact of change. 
The knowledge and value gaps as problematic predispositions, include untested prior knowledge (practice and academic), cognitive limitations (Lejarraga et al, 2020) and problems of understanding financial firms (Larsen, 2021), historic ways of thinking, and continued preference for finance only values (Gendron et al 2013).

CSR problems also arise because of internal factors such as the relative invisibility of financial firm intangibles (externally and internally), and the complexity of their interactions with financial resources in an intricate, connected, financial firm system (Chen et al, 2014). The intangibles include 'governance', 'leadership', 'culture', shared knowledge. It concerns their dynamic interactions and significant role in financial intermediation (Holland, 2019a) and in CSR change processes. These internal factors and issues exacerbate barriers to CSR change.

The recent history of change indicates there will be cases where financial firm top teams and employees cannot, or do not wish to, adjust fast enough to external CSR change pressures, and conceal this in their reporting (Herold et al 2021; Norberg, 2015). This was illustrated in the GFC (2007-08) (Holland, 2010), and Wells Fargo case (2010-2016) (Avery, 2016). Section 4 shows how negative interactions between external change and internal barriers contribute to historic and current CSR problems. Historic barriers to learning and knowledge creation have repeatedly recurred in financial firms and hindered constructive change (Antonacopolou, 2006). Learning from past mistakes, has been the exception rather than the rule in UK banks (Harris, 2002). The GFC in 2007-08 showed unfavourable interactions between financial firm top team learning, knowledge, design of core functions and products, and risk management (Holland, 2010). Barriers arose from the existing 'nature of finance' such as intense time pressures and sole pursuit of financial aims (Hendry, 2013; Luyendijk, 2016), and from the rate and complexity of change in technology and financial innovation (securitisation).

These conditions persist and show why in a world of CSR change, extensive knowledge and values gaps persist, and associated failures and inactivity on CSR change, continue to arise. They contribute to CSR problems such as Wells Fargo (Avery, 2016) and add to increased financial exposure to financial risk and weak risk management in financial firms. They negatively affect delivery of CSR oriented financial services and the wider finance function of the firm.

For example, ignoring CSR issues and focussing on financial aims alone can lead to declining performance and failure in financial firms (Kilic et al, 2015). In contrast, Simpson and Kohers (2002) found a positive link between measures for corporate social and financial performance in US banks. Cornett et al (2016) find a positive relationship between US commercial bank financial performances and their environmental, social, and governance (ESG) ratings.

The same external and internal issues contribute to problems of CSR oriented reporting to stakeholders. These include associated problems of partial narratives, communications, disclosure (internal, external) and perspectives (by practitioners and academics) on how intangibles interact with financial resources to contribute to desired financial and CSR outcomes. For example, Chief executives such as Harrison (2019, 2020) of Schroders and Rose (2020) of NatWest tend to focus their public discussion and public CSR reporting on CSR 'visibles'. These include metrics showing socially responsible attitudes and behaviour of top teams and employees, and the delivery of socially responsible financial products and services to customers. They involve discussion of the new role of existing 'invisibles' or 'soft' factors such as governance, culture or leadership in their CSR oriented financial activities. This use of partial narrative about single or few factors reflects a fragmented public response to change circumstances. More complete narratives about 'soft' intangibles and their connections are normally developed in private internal meetings between top teams, middle management, and employees, as well as private external meetings with shareholders and other stakeholders (Holland, 2017a,b, Chen et al 2014, 2018). 
Financial firms that are members of alliances producing CSR guidance such as PRB (UNEP, 2018) seek to ameliorate the above problems, but still face significant risks. Those firms who do not adapt fast enough to external CSR change pressures, or do not wish to adapt, are particularly exposed to risks arising from CSR errors or failure. This when combined with increased activism and political risks can lead to major impact on financial firm reputation, financial performance, and stock price.

\section{Problems at the level of financial firms}

The CSR problems discussed above arise in top teams, employees, customers, and stakeholders. They arise with their values, understanding, behaviours, and actions. CSR change problems contribute, in some cases, to increased financial risk, problems with financial services, and CSR reporting to stakeholders.

Thus, practitioners face major knowledge gaps or problems in understanding financial firms, such as banks, insurance firms and fund managers. They also face values gaps between conventional finance values and emerging CSR values. The knowledge and values gaps become evident during ongoing periods of gradual and rapid change (Chen et al 2014, 2018, Holland, 2010, 2017b, 2019a,b,c). Knowledge gaps arise in practice and academe between what is known and what must be known (Zack, 1999), when making and researching CSR change decisions. Values gaps arise between what is being done and what should be done relative to CSR aims.

The knowledge gaps and 'values' gaps about CSR change in financial firms arise in practice and academe due to the complexity and rapidity of external change (Holland, 2010; Bratianu, 2020) and because of internal barriers to change. They arise at the level of the individual financial firms, top teams, and other employees.

The knowledge and value gaps are reduced, in part by debates, actions, and guidance in, a global and national political process, and in specialist finance communities such as international banking. The gaps are being reduced in the finance industry, in part, by intergovernmental actions on CSR related issues (UN SDGs, 2016; EU, 2011); by national regulations, and by major civil society and stakeholder initiatives (eg Ethical Finance events). They are being moderated in specific sectors by financial community collaboration and self-regulation (eg EBF, GABV) (Streeck and Schmitter, 1985) leading to development of principles such as PRB, PRI, and PSI.

However, the knowledge and value gaps are exacerbated by the ongoing complexity and rate of change of these external change pressures both physical and social. They are intensified by the ongoing contested nature of the CSR debate in global politics (Dashwood, 2020). The 'solutions' proposed are still contested by those parties in wider society and the finance community who prefer financial values and financial market forces to dominate the CSR change agenda, or by those who do not accept the premise of CSR.

Thus, because of ongoing physical changes (global economy, climate, human systems) and a contested CSR debate, significant problems remain at the level of individual financial firms.

Top teams in financial firms recognise these conditions of complexity, rapid change and contested ideas, impair their cognitive capabilities (Lejarraga, Pindard-Lejarraga,2020) and employees in their firms. Larsen (2021) argued that bankers may not have the 'head space' or cognitive capabilities to deal with this complexity. They may struggle to deal with combined CSR issues, climate change and nature-based risks. Mathews (2021) argued that is never possible to fully understand this complexity and rapid unexpected change. There is no perfect transition plan for say CSR or climate change in a financial firm because it not feasible to know exactly what is going to occur and how to respond. It is difficult for practitioners to develop a holistic view due to the rapid and complex change processes 
arising with new CSR pressures, climate change and biodiversity. These exacerbate problems of understanding, managing, and explaining change in financial firms as complex systems (Mathews, 2021).

Practitioners prefer an incremental, partial, adaptive approach to understanding this complex external change and the way it interacts with ongoing internal problematic predispositions (Mathews, 2021). This fosters 'muddling through' (Lindblom, 1959) behaviour specific to each firm. This is reflected in the variety found by Zimmermann (2019) in sustainability motives, practices, and sustainability strategy content in German banks. These conditions create incentives for 'business as usual' behaviour focusing on finance issues alone. This incomplete and partial response to CSR problems exacerbates existing CSR problems by 'crowding out' pro-social behaviour (Bénabou, Tirole, 2006).

In case financial firms, these conditions lead to the dominant focus on visible and measurable factors in the firm. They result in a lower profile of 'soft', relatively invisible, and difficult to understand and explain intangible factors. Analysis is limited to a few factors relevant to current circumstances.

\section{What change is proposed in financial firms?}

This paper argues that knowledge and 'values' gaps and associated CSR problems can be ameliorated by an enhanced holistic understanding of financial firms and improved transparency about financial firms and CSR. The paper argues for integrated thinking (IIRC, 2013; VRF, 2021) in financial firms through development and use of a conceptual framework to form an integrated response to the above CSR problems. This holistic approach takes the form of a CSR oriented 'Behavioural theory of the financial firm' (CSR BTFF). This is a means to answer the research question, and reduce in part, knowledge and values gaps in practice and academe in complementary ways. It is a means to manage existing CSR problems and improve responses to CSR change pressures and unexpected events.

More specifically, at the level of the financial firm, the paper uses a set of connected metaphors (Morgan, 1997) as the basis for a conceptual framework to answer the research question. In metaphor terms (Morgan, 1997) the CSR BTFF is made up of 'Head', 'House', 'Community', and financial 'Machine' elements driven by CSR and finance purpose. The firm is seen as a set of dynamic connections and purposeful interactions between these elements. Thus, a combined metaphor and narrative approach is used to explore how financial firms function as complex systems.

The paper argues that major changes are required to the CSR predispositions in the firm. This requires an integrated combination of CSR oriented changes in the firm ('Head', 'House', 'Community'), are required to create a substantive CSR orientation to the financial 'Machine' in financial firms. The intense CSR change pressures also require that top teams think how CSR changes in the financial firm fully reflect the above CSR changes in the external social and economic order. They must develop resilience relative to the contested nature of CSR debate at all system levels.

The CSR BTFF develops an integrated narrative how CSR oriented strategic conditions and intangibles at the 'Head' and 'House' provide the purpose, structure, and resources in the firm. These support organisational processes for influence and information flows during everyday operational activities in the 'Community' of employees. They focus their impact on financial decisions and various CSR and financial outcomes in a financial 'Machine' The CSR BTFF explores how external change, and interactions between top team capabilities, behaviour, and impact on values, and behaviour in the internal firm community and external community, form key strategic dynamics. It discusses how they impact on interactions with other employees (middle management, front line employees), with customers, stakeholders, and activists, and on associated CSR problems. Purposeful connections and interactions between these factors in an integrated business model (IIRC, 2013) are means to deliver CSR and financial aims. 
Thus, the financial 'Machine' is now expected to make significant changes to reflect CSR issues. The established view of the financial 'Machine' and CSR has required firms such as banks, insurance companies and fund managers to develop long term stability in strategy and operations, to use this to generate financial value for shareholders. They intermediate financial capital and its risks between users and suppliers of funds. Their primary responsibility is to use this capability to produce desired financial services and products (loans, insurance contracts, equity funds etc). This financial activity underpins real economic activity. The above analysis above has shown how this idea of Corporate Social Responsibility (CSR) has developed beyond this traditional view and become an increasingly important dimension to corporate life (Carroll et al, 2010). In the case of the financial 'Machine' in financial firms this has involves changes to non-financial context and predispositions supporting the 'Machine'. It involves changes to CSR orientation of products, internal information and production, interactions between employees and with customers, delivery of financial services, and financial intermediation.

The CSR BTFF is based on empirical and theory sources. It is an embryonic conceptual framework to answer the research question, understand the complex system, and close knowledge and values gaps in practice and academe in complementary ways. This is a means to aid understanding and make the financial firm visible. It can reduce barriers and CSR problems, incentivise change, and improve responses to respond to gradual and rapid CSR related change pressures as well as unexpected events. It can be used to develop narrative content of integrated reporting or $<$ IR $>$ (IIRC, 2013,2021; VRF, 2021) relative to CSR issues.

This paper recognises that issues of climate change, biodiversity, and social and ethical responsibility are deeply connected in complex physical, natural, and human systems. Sustainability is required, inter alia, in climate, life forms, resource uses (water, land, food, energy, built environment), social organisation, and economic activity. Social and ethical responsibility is required at individual, corporate, and societal levels (global and national). As Arduini (2021) notes, resilience to shocks equally depends on sustainability in all these areas. The combined set of problems and systems are complex. This paper focuses on the CSR aspects of these shared problems. A parallel paper (Holland, 2021), uses the same approach to focus more on the climate change issues, thus providing a wider view of the shared issues.

\section{Research methods}

Section 2 outlines sources of data and use of qualitative methods to understand: the 'soft' infrastructure and intangibles of financial firms; their role in operational activities and financial decisions. It shows how these are the focus of CSR change and are means to reduce CSR problems. This section discusses the use of metaphor and narrative to succinctly communicate empirical insights about CSR change and problems and uses interdisciplinary theory sources to interpret empirical insights. These provide the basis to develop CSR oriented 'Behavioural theory of the financial firm' (CSR BTFF). This is a further development of a financially oriented BTFF (Holland, 2017b, 2019a,c). The CSR BTFF can be used to improve integrated thinking in managing financial firms and to support development of CSR disclosure in integrated reporting or $<\mathrm{IR}>$ in financial firms.

Insights from major problems in financial firms (see section 4 for details), and from practitioner and conference debates about CSR change (Ethical Finance, 2017-2021; and Green Finance, 2017-2021), are the basis to describe and explain CSR oriented dynamics and their complexities in financial firms. Other sources include the public debate about CSR by bodies such as the UN and EU and national governments. These sources collectively form the basis for developing an embryonic CSR BTFF. Many of these sources of data were collected during Covid-19. Silverman (2021) argues that this shows that in a digital age, being 'present' in the 'field' needs to be reconsidered. 
From the authors perspective this created many new opportunities for data collection as conferences such as Ethical Finance (2019-2021) and Green Finance (2019-2021) were recorded and available for viewing many times.

The approach in paper is comparable to the Kay and King approach (2020). It breaks down the complexity of the CSR change problem in financial firm and network system into four comprehensible metaphors or themes - Head, House, Community, Machine. It develops an integrated narrative for this - to develop a big picture of 'What is going on'. More specifically, the CSR change themes were manifest in cases as four change areas concerning CSR oriented changes: at the top of the firm ('Head'); to socio-technical context ('House') as structure and mechanisms; to interactions, processes, and working conditions (in 'Community'); and to financial decisions (in 'Machine'). It includes consequences and feedback. These, in turn, were connected in a larger change narrative. The use of metaphors (Head, House, Community, Machine) to convey the essence of the empirical themes reflects Morgan's (!997) approach to understanding complexity and change in organisations. The change themes also concerned changes to communication (internal, external), reporting, and 'ongoing external engagement'.

Within each metaphor, the grounded theory research process (Strauss and Corbin, 1998) develops comprehensible narrative to show 'What is going on' or happening in this specific area to understand how change occurs, risks and problems arise. Within each metaphor area, it focuses on a few factors and variables as important. These are developed from many financial firm cases, events, public debate, and pressure for change, and from literature and theory. The paper constructs an integrated sub-narrative around these factors for each metaphor and integrates all metaphors in a broader narrative. These are identified from empirical research and theoretical analysis.

An iterative process of learning between data, constructs, prior research, and theory was the basis to develop the CSR BTFF. The choice of the four metaphors (Head, House, Community, Machine) (Morgan, !997) used in the CSR BTFF was based on this iterative process for interpreting the financial firm system and its changes. The CSR BTFF forms an embryonic conceptual framework to analyse CSR problems and change issues in financial firms and probe how they can develop their CSR orientation. This involved developing grounded theory in an iterative research process (Strauss and Corbin, 1998) to find out 'what is going on here' ( Kay and King, 2020).

\section{An outline of a CSR oriented 'behavioural theory of the financial firm' - CS BTFF}

Section 3 briefly outlines how financial firms, and their employees can become corporate socially responsible (CSR) in a more systemic and whole firm way. This involves developing a firm-wide hypothesis (Poterba, 2021) about CSR change in the financial firm. The approach is based on a CSR oriented 'behavioural theory of the financial firm' grounded in empirical and theoretical narratives (Golden-Biddle and Locke, 2007). This consists of four connected empirical themes or metaphors (Morgan, 1997) of 'Head', 'House', 'Community', and financial 'Machine'. These are based on historic problems and current CSR issues facing financial firms. This empirical narrative illustrates core factors, structures, and dynamics in financial firms. It is interpreted using relevant literature to form a theoretical narrative.

Practitioners note that much of the public debate and change agenda has been about how to change the delivery of individual financial transactions and specialist financial portfolios to include CSR outcomes. However, they increasingly recognize that desirable CSR outcomes depend on more systemic changes throughout the financial firm (Rose, 2020; Harrisson, 2020). This requires the development of a holistic, systems view of the financial firm. This is a necessary 
condition to think about systemic change in financial firms such as banks (Breeden, 2019; Van Ast, 2019) and produce more complete and permanent changes in asset allocation and financial transaction activities, and in desired CSR outcomes associated with these. Practitioners change proposals match key variables and connections in the CSR BTFF. Their ideas can be set within the CSR BTFF frame to provide a coherent and integrated view of change.

In the following sections, CSR change is explored in two ways. Firstly, in section 3.1 The empirical narrative is briefly outlined to reflect the new dynamics of CSR change pressures on the financial firm and its employees. Secondly, in section 3.2 the paper argues that the explanatory power of the empirical change narrative can be enhanced by interpretation in an interdisciplinary theory approach (Knights and Willmott, 1997; de Bakker et al, 2019).

\subsection{A brief outline of the CSR BTFF - as an empirical narrative}

In this section a brief 'empirical narrative' of the CSR BTFF (Golden-Biddle and Locke, (2007) is used to illustrate core factors, structures, and dynamics in financial firms. The cases and 'empirical narrative' provide a holistic view of key factors and their connections and every-day or operational dynamics in the financial firm. They provide readers with a 'map' to navigate the paper.

Figure 1 illustrates a schematic view of the CSR BTFF. In metaphor terms this show connections and interactions between 'Head' , 'House' ,Community' and financial 'Machine'. It shows external change pressures, key strategic and intangible factors, and working conditions. This illustrates key CSR oriented factors in firms, their dynamic capabilities relative to CSR issues, how they are integrated, and how they enable financial decision actions in decision teams. It shows connections and interactions between factors in transforming financial resources in financial firms to achieve financial and CSR aims. The CSR oriented finance decision activities occur at whole firm, specialist portfolios, and transaction levels.

Practitioners in cases such as Rose $(2020,2021)$ at NatWest, and Harrison (2020) at Schroders have argued that changing financial firms to be systematically CSR oriented requires co-ordinated change in at least four critical areas of: 'Head' as top team understanding and response capabilities and observed top team behaviour; 'House' as sociotechnical 'organisation'; 'Community' as employee understanding and behaviour; 'Machine' as financial decisions and delivery of financial services. The following subsections explore each major metaphor as components of a fourpart empirical narrative.

\section{CSR changes in 'Head'}

The first part of the change narrative involves top teams ('Head') 'looking out' to learn about the nature of CSR, and about increasing external CSR pressures and climate change. Top teams actively engage with and learn from other top teams (peer groups), other members of elites in the financial community, and stakeholders in wider society. They learn about current and historic problems. The activities also involve 'looking in' and learning how to make changes in top teams ('Head') in terms of composition, diversity and capabilities of boards and executive teams. They involve 'looking in' and changing behaviour of top teams to change the 'tone' in the firm as part of the means to influence behaviour of employees.

\section{CSR changes in 'House'}

The second part of the change narrative involves change to the 'House'. Top teams use the CSR oriented changes in their learning, understanding, and strategic thinking capabilities to 'look in' make CSR oriented strategic changes to purpose, planning, structures, and resources. The latter involves changes to 'socio-technical' contexts and resources (Mumford, 2000; Mitleton-Kelly, 2003) influencing the use of financial resources.

The socio-technical infrastructure ('House') change consists of three clusters of strategic change. The first cluster includes changes to: firm wide social structure, culture as 'organising' means, and to knowledge resources; at both macro and micro levels. The second cluster concerns CSR oriented changes to control and influence mechanisms. These include communications and storytelling, top team behaviour, training, incentives ('soft' and 'hard'), formal control systems, as well as changes in culture as a means of controlling and influencing. The third cluster involves CSR changes to technology and impact on knowledge, social and financial process. These changes are strategically 
matched to changes in the external environment (Teece et al., 1997) concerning CSR change and the internal need to develop resilience in the face of uncertainty.

These CSR sensitive intangibles (internal, external) and control systems are critical to directing CSR oriented behaviour in employees, to create information in the financial firm, and make financial transactions possible. These choices help create a positive CSR 'atmosphere' in organisational conditions and their influence on employee behaviour and in interactions with customers.

\section{CSR changes in 'Community' - internal and external}

The third part of the change narrative discusses CSR change themes identified in critical areas within the 'Community' metaphor. This focuses on direct means for the promotion of CSR awareness and the pro-active use of firm wide interactions to ensure all major finance decisions are 'CSR aware'. The CSR awareness activities involve engagement, learning, use of good practice and culture, and self-monitoring. The CSR awareness activities and interactions combine with contextual influences above (from Head and House) to focus employee minds on how CSR aims can be incorporated with financial aims at the point of financial decisions. Engagement with customers reflects all these changes.

This community change being driven by top-down purpose for the firm, as well as 'bottom up' and network influences. This seeks to change the 'lived experience' and CSR purpose of individuals and teams in the firm and external communities, when interacting with each other and with customers and other stakeholders

In the first case, CSR change is being driven by top-down influences from increasingly committed, concerned, and informed boards and executives in financial firms. Top teams are concerned about how to directly change employee values, behaviour, and the nature of multidimensional social interactions in the 'Community'. This involves top team attempts to directly change the values, mindsets, and behavior of other employees to reflect CSR issues and become CSR oriented in their financial decision activities. These include using CSR changes in top team behaviour to create a 'tone from the top' and other direct means to promote 'CSR awareness activities' amongst all employees.

For example, leaders Rose $(2020,2021)$ at NatWest, and Harrison (2020) at Schroders promote CSR oriented changes to purpose, training, incentives, targets, metrics, timetables, and control systems. They mobilise formal and informal meetings, control mechanisms, and technology to promote these firm wide interactions about complementary CSR and financial aims. These actions create debate and stimulate learning in multi-level employee interactions in the firm and in customer networks. They focus minds on how CSR aims can be incorporated with financial aims at the point of financial decisions. Engagement with customers reflects all these changes. This is how they speed up the process and create urgency in change.

CSR change is also being driven by 'bottom up' and network influences from increasingly committed, concerned, and informed employees and customers. This is especially the case in employees under 40 in a very competitive 'market for talent', and amongst customers and stakeholders in in similar age groups. As result, both 'head and community' are driving CSR changes in the 'head, house, community and machine'

The 'community' metaphor provides insights into the 'lived experience' or 'life' of employees, customers and stakeholders involved in CSR change in behaviour in internal and external 'communities' or social organisations. It highlights the main factors at play and their connections in the CSR change process in the 'community'. It concerns how they generate social forces to change behaviour and financial decision practice in the firm and with customers.

\section{CSR changes in financial decisions and financial 'machine'}

The fourth part of the change narrative discusses CSR change themes identified in the financial 'Machine' metaphor. The change themes concern CSR changes to financial decisions, especially their structure, processes in routines, and outcomes.

The 'Machine' structure is made up of a firm hierarchy of connected financial decisions, decision routines, decision conditions, and decision processes. This integrated 'Machine' and its processes, within organisation structure, are designed to produce and deliver financial products, to manage risk through financial intermediation, and deliver finance functions for the economy.

The above change themes in Head, House, and Community concern CSR changes to the non-financial context of the financial 'Machine'. This integrated non-financial social system and financial 'Machine' are designed to jointly guide CSR oriented financial decisions and manage risk throughout the firm during financial intermediation (Lewis and Davies, 1987). They are intended to jointly produce and deliver outcomes such as CSR oriented financial products and desirable CSR outcomes amongst employees, customers, and other stakeholders. 
The paper discusses how financial firms use the non-financial context, to support CSR oriented behaviour and drive financial decisions (single, portfolio, firm) in a financial 'machine'. More specifically, the integrated non-financial social system elements influence the social structure, purpose, values, and 'atmosphere' of the financial 'Machine'. They influence CSR conditions (attitudes, mindset, behaviour, motivation) amongst employees and teams, during their connected financial decisions and when transacting with customers.

They influence the hierarchy of financial decisions in the firm (firm wide, portfolio, single), as well as decision routines used in all these hierarchy levels. This includes CSR oriented financial strategy, capital allocation and overall financial risk management of the whole firm by top teams. It concerns CSR oriented capital allocation and risk management of specialist financial portfolios (assets and liabilities) by middle management teams. It includes specialist single transaction decisions by front line teams. All of these are supported by back-office teams for information, risk, contracting, and transaction services.

Financial firms thus use intangible social and knowledge resources in the CSR oriented 'Head', 'House' and 'Community', to create information, control behaviour, and reduce information asymmetry and transaction costs at the point of decision making by each specialist team. They do this to enhance liquidity management, diversification, and risk management. This creates conditions for financial intermediation and hence the transformation of financial capital and its risks. (Holland, 2019a).

This collective system change is means to ensure there are many internal firm CSR pressure points - policy, culture, teams etc - at the point of financial decision making at all levels. This prevents falling back into traditional finance logic alone. All teams must adopt CSR values and aims and use them in complementary ways with finance values and decision logic in everyday financial decisions.

These support production of CSR oriented outcomes and use of financial resources, consistent with CSR aims and financial aims (value and risk) in the financial firm. This highlights the main non-financial contextual factors at play and their connections in CSR change in the financial 'Machine'. It concerns how they change financial decision behaviour and practice in the firm and with customers. This is the means to deliver complementary CSR and financial aims. Thus, the specialist financial function of the financial firm in the economy remains central but is adapted by the non-financial context to reflect CSR concerns.

\subsection{Theoretical analysis of the CSR change narrative - An Interdisciplinary approach}

This paper argues that the explanatory power of the empirical change narrative can be enhanced by interpretation in an interdisciplinary theory approach (Knights and Willmott, 1997; de Bakker et al, 2019). This is an alternative and complementary means to understand multi-faceted aspects of change in the financial firm complex system. A focussed set of relevant literature is used to interpret the empirical narrative, and this analysis forms a theoretical narrative (Golden-Biddle and Locke, 2007). The combined narratives form the overall conceptual framework in the shape of the 'CSR Behavioural theory of the financial firm' (CSR BTFF).

The theoretical interpretation seeks to tell a 'theoretically equivalent' story to match case insights. Literature and theoretical analyses are focused on and aligned with the structure of the empirical change narratives.

Theoretical interpretation in the paper begins by using systems theory (Mumford, 2000; Mitleton-Kelly, 2003) to analyses the nature of ongoing firm complex systems and operational narratives. These are the focus of change and theoretical interpretation of change. This highlights the need to manage change in the firm as a complex system.

The empirical narrative for change is outlined in four parts to match the structure of the four-part empirical narrative for change. The following subsections concern CSR oriented changes to: Learning, Strategic thinking, Planning and Purpose in top teams ('Head'); Contextual resources, and Mechanisms ('House'); Interactions and Conditions (in 'Community'); and Behaviour and Financial Decisions( in a 'Machine'). The structure of this grounded theory insight provides opportunities for researchers to use their specialised disciplines to analyse the phenomena.

Systems theory ( Mumford, 2000; Mitleton-Kelly, 2003; Saltmarshe, 2018) and Bourdieu's theory (1986, 1990), are used as two complementary frames for holistic analysis of the structure of the empirical change narrative. The 
paper aligns terms and concepts from systems theory and Bourdieu's theory with equivalent empirical terms and concepts from cases concerning system elements and change.

Additional specialist theories and literature sources are used within these frames in an interdisciplinary way (Knights and Willmott, 1997; de Bakker et al, 2019), to explain each segment of the four-part empirical change narrative. The combination of theory and literature sources expands interpretation of empirical phenomena and forms the basis for an equivalent 'theoretical narrative' (Golden-Biddle and Locke, 2007) about the financial firm system and its CSR oriented changes.

For example, interdisciplinary resources used in part 1 or 'Head' metaphor of the change narrative, include, inter alia, literature on; the firm as a complex system (Mumford, 2000), and as a learning organisation (Pedler et al, 1997). In part 2 or 'House' metaphor they include literature on systems and organisational change (Burnes, 2004;Mumford, 2000; Mitleton-Kelly, 2003; Holland J. H, 2014), and changes in culture (Schein, 2004). In part 3 or 'Community' metaphor they include sources on storytelling (Boyce,1996), and social interaction and change in behaviour in social contexts (Bourdieu,1990; Stones, 2005). In part 4 or metaphor on financial decisions in a financial 'Machine') they include literature on the theory of the firm (Barney, 1991; Hart, 1995; Teece et al, 1997), behavioural finance (Statman, 1999), and theory of finance (financial intermediation) (Scholtens and van Wensveen, 2003; Holland, 2019b). These sources were aligned and matched to the empirical insights.

These connected social resources and knowledge of these, and their mobilisation contribute to social forces which drive agent and team financial decision action in the financial firm and networks relative to financial, CSR and climate change aims. This reflects Silverman's (1970) view that social reality is socially constructed, socially sustained, and socially changed. In Bourdieu's (1990) terms social resources concern 'fields' representing the structure of social relationships in the firm and external networks. They represent agent social capital (denoting connections and networks) and symbolic capital (denoting reputation and prestige) in the field. Social structures and knowledge of these are critical to informing action by financial firm top teams and employees about CSR oriented change. Bourdieu (1990) argues that agent habitus, as knowledge of, and a way of perceiving, the everyday familiar social world, is both a structuring structure and a structured structure. Financial firm top teams have many interactions within financial firm social or field context, with other team members in the firm about CSR issues and their relationship with conventional financial activities. They have many interactions with CSR concerned customers (on the fund supply and demand side) in financial markets, with CSR active agents in similar financial firms, and with CSR oriented stakeholders. The CSR awareness activities and interactions within field context are combined means to structure habitus, expertise, and social and symbolic capitals in new CSR oriented ways. They structure 'Head', House' and 'Community' and their impact on decisions in the financial 'Machine'. These in turn structure working conditions for employees. They structure the meaning of CSR oriented information, action, behaviour, financial decision, and transacting activities for employees within internal firm and external network or market social fields. Top team, employee, and customer experience of this structuring plays a role in further developing social structures for CSR and financial aims.

Thus, the paper directly studies a broad idea of 'behaviour' in research on financial firms and financial intermediation. 'Behaviour' in the CSR BTFF refers to actions by individuals and teams, in financial firm organisations, with stakeholders in external networks, and in financial markets. As a result, the empirical insights on behaviour in these domains are analysed using organisation and social theory, as well as ideas expounded in behavioural finance theories (Statman, 1999). This reflects Hirshleifer's (2015) argument that there is a need to move 
from behavioural finance to social finance, including social norms in the study of financial behaviours. He notes 'Especially, the time has come to move beyond behavioral finance to social finance, which studies the structure of social interactions, how financial ideas spread and evolve, and how social processes affect financial outcomes'.

The approach does not seek to "integrate" the interdisciplinary theory perspectives. It is not feasible to develop a "meta theory "of the financial firm and its changing knowledge, social and financial resources based on many theory sources. There are too many epistemological and ontological differences (Morgan and Smircich, 1980) between the assumptions of say symbolic and contextual analysis underlying sociology and management theoretical sources and assumptions of positivism or normativism in finance theory. The empirical narrative for change is explained in each major part (of four) by distinct theory sources. The full change narrative is explained by systems theory and Bourdieu theory. Each theory source provides novel insight into the empirical phenomena. As a result, the paper demonstrates that the integrated grounded empirical narratives provide new ways of potentially "connecting" and combining these interdisciplinary theory sources, in a way which adds to our understanding of the CSR change phenomena in financial firms. 
Figure 1 - Main elements of CSR BTFF - and dynamics between key factors

- Theoretical narrative - based on empirical narrative

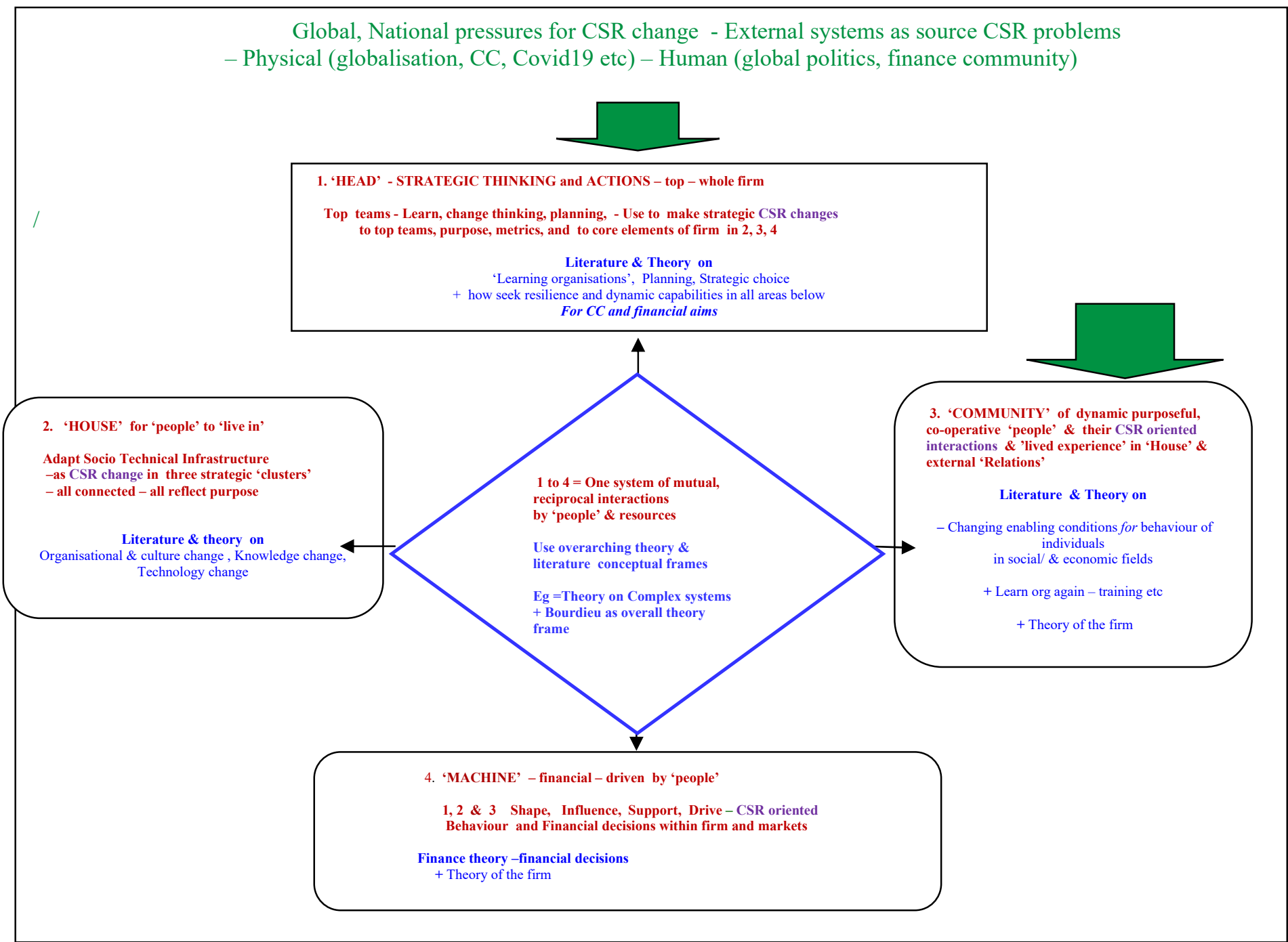

4. What are CSR problems in financial firms - historic, continuing?

Section 4 uses the CSR BTTF to succinctly summarise and connect the main CSR problems arising in financial firms. Negative interactions between external change and problematic internal predispositions play a major role in historic and current CSR problems. As a result, CSR problems arise in key parts of financial firms such as the 'Head', 'House', 'Community', and financial 'Machine'.

The problems are historic and current, with the latter concerning how to implement new ideas of CSR in financial firms. The CSR problems arise in top teams, employees, customers, and other stakeholders. They arise with their values, understanding, conditions, behaviours, actions, and outcomes. The CSR change problems contribute to financial risk and to problems of CSR reporting to stakeholders.

The discussion thus illustrates the conceptual frame developed in the paper in the form of a CSR BTFF. This structure and analysis of CSR problems provides new insights into how CSR reporting by financial firms can be critically appraised and improved. 


\subsection{CSR problems in key parts of financial firms}

\section{CSR problems in top teams or the 'Head'}

Major CSR related problems of purpose, and motivation arise in top teams, and these spread throughout financial firms. There have been issues of negative CSR related behaviours and policies of top teams and their impact on employees, and on employee behaviour with customers. These arise in conjunction with problems of understanding the social and knowledge infrastructure of the firm, especially with invisibility of intangibles during rapid change. The problems of understanding financial firms contribute to knowledge gaps in both practice and academic fields.

Several authors have identified these difficulties in implementing CSR policies in core activities in financial firms (Thompson and Cowton, 2004; Scholtens, 2009; Wu and Shen, 2013; Tran, 2014; Avery, 2016). Financial firms face knowledge-based problems of communication when reporting on CSR, climate change, and financial value creation, (Gray et al, 2001; Avery, 2016; Michelon et al, 2015).

Historic problems arose in firms such as RBS and Wells Fargo due, in part, to top team ignorance, indifference, or hypocrisy about CSR. The GFC showed how knowledge and perceptual barriers in top teams arose from ideological positions, short-term views, and dominance of conventional finance theory with sole focus on shareholder wealth (Holland, 2019a). Problems have emerged in clarifying a combined CSR and financial purpose of firms and establishing motives for pursuing CSR. This creates conflicts between CSR and financial performance aims and varies with CSR motivation. For example, Wu and Shen (2013) note three CSR motives in US banks, namely, strategic choices, altruism, and greenwashing. They find the relationship between CSR and financial performance is positive, non-negative, and non-existent, for each specific motive.

Other knowledge-based barriers exist for financial firms undertaking CSR programs. Tran (2014) noted problems of understanding costs and benefits prevented Chinese banks from engaging in CSR. They include financial costs of CSR and difficulty of measuring benefits, financial or social. The absence of a national policy and regulatory structure with sanctions and incentives were key barriers. These problems are expected to decline with UN (UNIDO, 2019), and EU (EU, 2011) leadership on CSR. They are expected to decline with collaboration amongst financial firms to develop guidance or principles on how to understand and analyse common CSR practices, costs, benefits, and impacts (eg PRB, 2018).

However, climate change, Covid-19, and technology change reveal how problems continue to arise in implementing CSR ideas with employees and customers. For example, Fancy (2021) as ex head of sustainability at Blackrock expressed considerable scepticism about practitioners and market forces setting the rules of the game in areas of ESG (Environmental. Social, Governance) and closely associated CSR issues. In his experience at the heart of one of the largest investment 'machines', fund managers managing ESG funds were still dominated by short term financial incentives, and nearly always chose the wealth gain over the ESG gain (Rushe, 2021).

As discussed in section 1, this situation has stimulated transnational bodies and governments to act as referees to set the rules and interpret and monitor compliance with the rules of the game. Continuing CSR scandals are leading governments to legislate in areas such as financial firm duties to consumers (FCA, 2021). They may also use various professional guidelines (say PRB) to legislate on CSR behaviour at the top, amongst employees and with customers, and impose large fines on those who break the rules. They may have to impose CSR and carbon taxes on all financial firm financial transactions for a real change in in incentives, actions, and outcomes.

In terms of the climate change issues in CSR, WWF (2021) research showed that over 80\% UK FTSE 100 companies are on a pathway to produce $3{ }^{\circ} \mathrm{C}$ warming. The voluntary approach by the private sector is not working, 
thus highlighting the urgent need for the UK government to pass laws requiring large companies to publish their net Zero plans to achieve Paris $1.5^{\circ} \mathrm{C}$ aims (2015). The same approach is required for wider CSR behaviours. This includes all large international financial firms and their corporate clients in the UK. The plans must be verified by science-based and social science research organisations. Such legislation would intensify and enhance engagement between financial firms and corporate clients on CSR oriented change.

The Covid-19 pandemic in 2020-21 showed how many connected CSR opportunities and problems arose in financial firms. As the Covid-19 pandemic struck in March 2020, top teams at NatWest (RBS) (Rose, 2020) and Schroders (Harrison, 2019) were able to exploit prior strategic changes about CSR purpose and resilience to shocks. These concerned changes made to technology, work life balance of employees, and behaviour to customer in the period 2010 to 2020 . They used these to make very rapid decisions, often in 24-to-48-hour periods, about firm wide working conditions, and use of technology, for working at home, for team working, and for customer interactions.

This created opportunities for top teams to renegotiate employee contracts and customer conditions, work conditions and potentially take all benefits of productivity gains for top teams and shareholders. The response of financial firms to this new situation will be a major test of whether their CSR policies have substance or are a form of 'CSRwashing' (Mattis, 2008; Pope et al, 2016)

\section{Internal 'Community' CSR problems - Employees and CSR}

There are many ongoing problems of balancing shareholder wealth aims and stakeholder CSR aims, especially with employees. Pay and inequality issues within financial firms remain major concerns. Pay gaps between top teams and employees is very high in financial firms. Anderson et al (2018) notes in top 10 US banks,

' that pose the greatest risks to our financial system, the average pay gap was 265 to 1 in 2017. Among the four giants at the top, the average ratio was 319 to 1. '

Despite public and political pressure, top teams still mobilise shareholders to defend them against external pressures and support them on pay and top team incentive schemes (Anderson et al, 2018). The gender pay gap also continues to be a major issue. Wright (2018) analysed the gender pay gap data at nearly 400 firms from across the UK financial services industry and commented that the,

\footnotetext{
'..financial services sector performs worse than the rest of the economy on every aspect of gender pay gap reporting... highest average pay gap is at the 27 investment banks... while in more consumer-facing sectors such as insurance or consumer finance the pay gap is significantly lower...... women represent little more than a quarter of employees in the top quartile by pay in financial services, significantly lower than the rest of the economy.... At nearly three quarters of firms, women represent less than a third of the highest paid staff...... there is a structural problem in women progressing from the mid-level to the very top.....the low level of female representation $\ldots$ is flattered by the even worse gender balance on executive committees'
}

Covid 19 during 2020-2021 accelerated digitisation processes in financial firms. This raised CSR issues concerning employees. Increases in 'social distancing', remote working, and video communication, changed working experience of all employees. Some of this is welcome by employees in terms of work-life balance, gaining some control over the location and timing of work, and how it can be divided between home and office (Jones, 2021). Some of this change is not welcome. Firms may experience major problems in safeguarding employee wellbeing and being conscious of potential mental-health issues in a work at home world. They may experience problems in ensuring employees are engaged and motivated and in monitoring safety of employees (Jones, 2021). Employees may face wage reductions and lose their jobs as productivity is increased.

This is a major CSR challenge for financial firms and their top teams concerning employees and other stakeholders. It is a major test of whether combined CSR and economic change in the firm has substance or is 'CSRwash'. The latter will occur if the social and economic gains of the change process are only reflected in 
financial gain for shareholders and top teams. They will occur if the change becomes an opportunity to impose more precarious working conditions on employees.

If top teams in financial firms wish to achieve their CSR aims, they must be able to articulate a clear policy about this change in work, and how it varies with different tasks and teams such as top teams, middle management, customer facing functions, back office, risk-management, and market facing trading divisions. They must agree the change policy with employees to reflect new employee work preferences, whilst exploiting productivity gains.

This will require considerable sensitivity by top teams in terms of communication, building the internal 'community' post Covid-19, and balancing autonomy, and accountability issues with employees (Jones, 2021). They must report to stakeholders, such as shareholders, CSOs, and regulators, how their actions correspond with agreed CSR policies (on pay and gender equality, work conditions and contracts) and how authentic and evidence-based actions advance a CSR agenda of substance rather than hinder it.

\section{External 'Community' CSR problems - Customers and CSR}

Financial firms continue to exploit technology change pressures - with new strategies designed to reduce costs, hold onto the existing customer base, and maximise the financial value of products sold and delivered. In the case of banks (Rawstorne, 2015), this has involved strategies such as 'automating' branches with series of 'smart' self-service machines supported by 'experts' via phone or video. The main job of 'experts' is to accustom customers to using the new technology, to complete a wide range of transactions, acquire information for the firms, and encourage customers to transfer to internet banking and a wider set of products. This approach transfers 'processing' tasks and risks to customers. This exposes customers to new technology risks, as previously familiar local branch staff supporting transactions are replaced. Problems of basic transacting arise with technology novices amongst customers and with some expert customers. Rawstorne (2015) notes that 'Banks claim they are making the lives of tech-savvy customers easier....But most customers find the machines deeply irritating and alienating'. From the customer perspective, this is a prelude to more dramatic change. As customer use of the automated branch falls and they migrate to smart phones, card use, and full internet banking, the bank can justify closing the bank branches and ATMs, removing paper statements, and force customers to use card or 'smart phone' services (payments, account statements etc). The bank is effectively limiting customer choice (channel use, mode of processing transactions, products, and services) to a range in which bank defined technology solutions are the only alternatives.

Such 'digitisation' has worked for customers below 40 years or so but caused problems for older, conservative, less mobile customers. Age UK (2018) argued that customers in their 50s, and older, require socially responsible banks with staff who can listen to them, branches that are accessible, banks that make reliable use of their information, and banks that do not have product age limits, and who design financial products for later life.

The experience of Covid 19 during 2020-2021 accelerated the digitisation process as 'social distancing', remote working, and video communication, changed the experience of all age groups. It has forced many financial firm customers to become familiar with the digital world. For example, in the case of banks, this led to increased productivity through drastic reduction in use of cash, accelerated bank branch closures, and increased use of internet banking. Banks may argue this intensifies their focus on customers and increases the trends to ethical and responsible banking. However, the evidence for the latter has yet to emerge. Rolfe (2020) 
found that the technology change during Covid-19 accelerated the ongoing erosion of consumer trust in banks. Financial firms focus on economic gains and take benefits and transfer costs when interacting with customers. This shows a failure in relating CSR values and aims to financial values and aims when faced with rapid and urgent decision making. Financial values continue to dominate.

From the bank perspective the increased 'digitisation' can increase the profitability of the economic relationship, with retail customers and small businesses such as restaurants. As use of cash declines very fast due to Covid and customers increasingly use new payment technology to transact, this increases power of banks to control payment fees to customers, and technology fees to retail businesses. The lack of alternative widely used (non-bank) payment means, and of competition between banks on cost of payment services, and banning of surcharges (EU, 2015); means that businesses may transfer the extra cost (over cash) into prices to customers to protect their margins.

The rapid shift to digitised services, and increased software complexity in ageing systems, has also created IT vulnerabilities in terms of IT failures, service outages, and IT errors. The IT problems at RBS, Nationwide, HSBC, Barclays, TSB, and Lloyds bank from 2012 to 2018 reflect this. These IT vulnerabilities have in turn created new opportunities for fraud and hacker attacks. For example, the FCA fined Tesco bank $£ 16.4 \mathrm{~m}$ after an attack in 2016 (Guardian, 2018).

Customers have faced the costs of such outcomes immediately and have often been blamed for problems. They then have had to rely on parties such as Ombudsmen, Regulators, and CSOs such as Which? to defend them - rather than banks correcting problems and paying compensation immediately. The idea of social responsibility to customers has been a low priority despite the banks effectively forcing customers to migrate to digital banking. However, in 2017-21, major UK banks such as HSBC, and NatWest (RBS) faced significant public and media pressures on these matters led by UK consumer champion Which? In 2019 the major banks covering many UK customers adopted a voluntary code of conduct requiring them to refund fraud victims in full if they have shown reasonable diligence (Shaw, 2019). However, problems continue. Aldasoro et al (2021) of the BIS reported that financial firms were hit by hackers relatively more often than other sectors during the Covid19 pandemic.

\section{'Machine' - Financial exposures, risks, and CSR}

Such CSR related problems can lead directly to financial risk and financial value problems for financial firms. This demonstrates the need to jointly consider - interactions between nonfinancial resources and financial resources - and CSR and financial aims. A failure in achieving CSR outcomes, leading to negative effects on; relations and reputation with customers, and on motivation and capabilities of employees; can impair the financial function of a financial firm. It can reduce a firm's ability to secure financial resources (say deposits) and impair the ability to allocate them to new lower risk and higher financial margin products (say providing credit cards or loans to existing customers).

These can combine with employee problems (understanding, motivation) to increase financial risks in financial intermediation, impair financial performance and reduce stock prices. The GFC demonstrated how issues of perception, confidence and risk in financial firms are linked. Financial firms such as banks are more likely to be influenced by the risks of damage to customer relations and reputation compared to non-financial firms. They are more vulnerable to limitations in decision capabilities and risk behaviour of employees. They are more vulnerable to negative reactions from stakeholders (as fund suppliers and users, as citizens) when 
combined financial and CSR risks become public. They are more vulnerable, when their links and relations with corporate clients or investee firms with inappropriate CSR activities and outcomes, become public.

There are recent examples of financial firms such as Wells Fargo (in 2010-2016) exploiting change opportunities to develop huge knowledge, informational and transactional power relative to retail and small business customers and then using these capabilities in irresponsible, unethical, and fraudulent ways. The Wells Fargo case (Avery, 2016) shows how vulnerable financial firms are to threats to their reputation once this behaviour is revealed (Thompson and Cowton, 2004). The RBS case in the GFC and Wells Fargo case reflect bank misuse of their power, knowledge, and transactional advantages over customers to reduce immediate costs for the banks, boost profits, and forego delivering the substance of its explicit CSR promise to customers. This hypocrisy and deceit are short sighted given the long-term reputational costs for banks and loss of friendly direct contact with customers (Thompson and Cowton, 2004). As a result, financial firms pay particular attention to reputational and relationship risks caused by CSR related errors or misbehaviour which can affect confidence in their supply and use of financial resources. As Carnevale et al noted (2012) banks have changed their approach to CSR.

'they are now more careful to manage the direct and indirect risks arising from lending to firms exposed to environmental and social problems. Some authors argue that while, in the past, CSR issues did not seem to involve the banks because their production process and products were unrelated to risks and/or effects directly related to CSR, today banks are increasingly exposed to the dynamics of CSR: either directly as companies themselves, or indirectly through financing activities of companies not considered "virtuous"

Covid-19 and climate change have posed new CSR issues and financial risks for financial firms. Increases in bad loans for banks, in stranded assets for fund managers, in insurance pay-outs, puts pressure on the capital of banks, fund managers and insurance companies. This requires pro-active action with struggling customers, to manage or remove such financial risks on their balance sheets. This will require considerable sensitivity by top teams in terms of engagement with customers facing Covid and climate change problems. They must report to stakeholders how their actions correspond with agreed CSR policies and how they advance a CSR agenda. They must report on how this allows the firm to continue to create financial value with its customer base.

\subsection{Taking a systems view}

The paper takes systems view (Mumford, 2000. It views the metaphors as describing a connected system of dynamic interactions between 'Head', 'House', 'Community', and financial 'Machine'. Historic and current cases illustrate the multiple interactions arising between 'Head', 'House', 'Community', and financial 'Machine' in financial firms. RBS (Holland, 2010) and Wells Fargo cases (2008-2016) (Avery 2016) show how CSR problems arose in dynamic interactions between intangible factors in 'Head', 'House', and 'Community' and how they contribute to financial risk problems in the financial 'Machine'. Hence financial firms recognise they must manage the whole firm as a connected system to achieve coherent CSR change. The NatWest (RBS) and Schroders cases show how firms made prior decisions over 2010 to 2020, about CSR and Climate change orientation of their 'Head', 'House', 'Community', 'Machine' and overall firm system. These strategic choices created resilience and flexibility relative to Covid-19 changes and created many new opportunities and problems in the pursuit of CSR and financial aims. 


\section{How change behaviour in financial firms - to be CSR oriented throughout the firm?}

Section 5 uses a change narrative to discuss how to change behaviour in financial firms to be CSR oriented, in a systematic and holistic way at all levels. This change narrative and discussion uses the CSR BTTF to succinctly summarise CSR change processes in each area and interactions. It notes how CSR behavioural change can be managed in key parts of financial firms such as 'Head', 'House', 'Community', and financial 'Machine' during interactions between these elements. Within each metaphor, it develops narrative to show 'What is going on' or happening in this specific area to understand how change occurs, risks and problems arise. This is a basis to think and act to reduce the likelihood of CSR change problems occurring in each area and across the whole firm system and external networks. This structure and holistic analysis provide new insights into how CSR reporting on change can be critically appraised, and how such reporting can be improved by financial firms.

\subsection{CSR changes in the 'Head' of the financial firm}

The first part of the change narrative discusses change themes identified in six critical areas within the 'Head' metaphor. These include CSR oriented change at the top involving external collaboration and learning, purpose, governance, capabilities, and behaviour. Top teams 'look out' and 'look in' (Pedler et al, 1997) to learn how to change purpose, governance, capabilities, and behaviour, in an incremental adaptive way over time.

Section 1 has noted how change narrative involves top teams ('Head') in an active debate and collaboration in the finance community and wider society about CSR issues. It involves top teams ('Head') 'looking out' to learn how the increasingly intense change pressures are changing the nature of CSR issues in firms. They learn how external change and problematic internal predisposition contributed to CSR problems in financial firms in recent history (see Section 4). Top teams are actively engaging with, and learning from, peer groups, elites, and shareholders in the financial community, and from stakeholders in wider society. They learn about risk, uncertainty, and complexity induced by CSR change pressures, and associated climate change, biodiversity concerns, technology change, and regulatory changes. This involves working in alliances within and across specialist finance sectors and with wider society, to understand CSR problems and CSR change issues, and develop the 'rules of the game'.

The first part of the change narrative also involves top team 'looking in' and learning how to change the CSR orientation of critical internal factors and their predispositions. If they can, they make the changes together in an incremental adaptive way over the same time. They 'look in' and learn how to make changes in top teams ('Head') in terms of governance, composition, diversity and capabilities of boards and executive teams. They learn how to make CSR oriented strategic changes to strategic purpose or mission and vision. This involves changes to strategic thinking, and metrics. They learn how to change top team behaviour and create a 'tone from the top', as part of the means to promote 'CSR awareness activities' amongst all employees.

Pathan (2009) showed how, in financially oriented US banks, CEO power to control board decision, negatively affected bank risk-taking. This was evident in the GFC when CEOs and 'dominant coalitions' (Cyert and March, 1963) in banks such as RBS and BOS exhibited such power and led to bank failure (Holland, 2010). Post GFC, there has been wide recognition in corporate governance reform that this power be counterbalanced in new boards and executive teams ( FCA, Senior Manager's Regime, 2015). Top teams must be able to develop a consensus view based on challenge in CSR debate in the firm and externally. They must manage CSR change pressures and associated climate change, biodiversity, and technology risks, and at the same time deliver core financial functions and financial value. 
As a result, case firms such as NatWest and Schroders and corporate members of specialist financial sector alliances ( eg GFANZ, 2021) are learning in a collaborative way about the nature of CSR pressures and climate change risks. Top teams are learning together, internally, and externally, how to make changes to firm purpose, function, and planning. They are changing the 'Head' in terms of leadership, diversity and composition and governance of board and executive teams, to create the capabilities to deal with CSR pressures, technology change, and climate change risks. This is changing the CSR conversation with external stakeholders and within the firm.

As noted in section 1 there has been much collaboration in the finance community on CSR amongst banks, fund managers, insurance firms, and other specialist financial firms. This involves developing CSR related principles such as PRB (UNEP, 2018), professional standards (Bogan, 2018) There has been much pressure for CSR change by intergovernmental actions (UNEP, 2018; EU, 2011) and growing pressures from CSOs. Thus, 'Looking out' (Pedler et al., 1997) concerns top teams in financial firms co-operating and learning together in peer group and sector specific CSR change alliances or "communities of practice" (Lave and Wenger, 1991).

Shen et al (2016) find that CSR oriented banks overwhelmingly outperform non-CSR banks in terms of return on assets and return on equity. This suggests that those bank top teams that collaborate and learn about CSR frame and policies, are more likely to create additional financial value than those who do not collaborate. Such collaboration and collective action on CSR are essential given the likelihood of considerable variation possible between financial firms on strategic change. Zimmermann (2019) argued that this variation was caused by varying bank top team motives in Germany stimulating different CSR and sustainability practices. The achievement of finance industry targets for CSR change will not be achieved unless this variety is set within a wider agreed frameworks and action plans for CSR change.

The collaborative activities provide means for top teams to learn from other top teams and other members of elites in the financial community about risk, uncertainty, and complexity induced by CSR change pressures and by other associated changes. Wiœniewski (2015) argues that;

'CSR is a crucial part of the process of risk management, which involves identifying appropriate risks, defining their influence and showing means of reducing the likelihood of risk and its consequences'.

In the financial firm cases, the CSR change problems went beyond issues of risk and risk management. They concerned major uncertainties created by unexpected shocks such as the GFC and Covid-19, as well as very rapid and comprehensive changes in uses of technology. Sections 1 and 4 show that CSR risk and major problems of resilience arise from the impact of rapid and complex change alone. They also arise when such rapid and complex external change combines with problematic internal predispositions and internal barriers to change in firms.

Practitioners argue that top teams in financial firms must 'look out' and learn about and understand the nature of the complex change problems and risks they face (Ethical finance, 2018, 2019). Breeden (2019) argued that given the nature of the risk and uncertainty with CSR and CC concerns, the strategic response has to be led from the top in a holistic, forward looking, approach (Integrated thinking). Top teams must learn and use new insights from the wider public debate and recognize. They must manage CSR risks associated with preference for 'business as usual', and domination of historic priors, financial values, and purpose.

Financial firms can use the example of climate change scenario analysis (TCFD, 2017; IPCC, 2018) to think about wider CSR risks. CSR risk analysis can be based on scenario analysis or simulations of socially irresponsible behaviour with say employee and customers in sectors such as retail banking, fund management or insurance. Major firms and industry bodies could assess risks caused by the likely responses of pressure groups, governments, regulators, markets, and others. They could examine extreme hypothetical change circumstance and explore the resilience of the firm to 
uncertainty. This integrated thinking about CSR risk and uncertainty must be communicated throughout the firm to avoid reputation risks (Bebbington, 2008) and financial risks.

Practitioners such as Vaccoro (2019) of Triodos bank and Haresnape (2018) of Gatehouse Bank (Ethical Finance, 2019) argued that practitioners are very aware they must learn how to avoid the negative behaviours and attitudes manifest in the GFC and cases such as Well Fargo. Top teams must avoid creating a negative CSR 'tone' to organisational factors such as: hierarchical power relations, culture, team spirit, shared knowledge, internal communication and feedback systems, control systems, incentive schemes and many others. They must avoid these organisational factors creating a negative 'team spirit' in the wider firm and specialist decision teams about CSR aims. Rice (2019) argued that individuals at all levels in financial firms have to ask what they can do to change their behaviour and activities to avoid such problems and reflect CSR concerns. Employees at all levels have to be persuaded to buy into CSR ideas and aims to change their mindset.

This learning at the top also requires critical thinking in top teams in financial firms about the dominance of conventional finance theory and ideas of finance capitalism. Stakeholder theory (Donaldson \& Preston, 1995) and literature on corporate legitimacy (Power, 2003; Preda, 2005) can help top teams learn and develop their ideas. The pressures for change indicate that financial firms require a more critical stance on shareholder wealth aims and associated short-termism. They require ideas from the external debate about CSR and its costs and benefits to be diffused through the firm and be directly employed at the point of financial decisions. This requires incentives to reflect the new relationship between of CSR and financial aims. Incentives - especially their underlying philosophy- have to formally reflect this balance to avoid pro-social behaviour reflecting CSR being 'crowded out' (Bénabou and Tirole, 2006) by continuing and intense financial pressures.

These learning and critical thinking capabilities are means to enhance top team understanding about CSR related risk and uncertainty, and how these impact on employee morale; customer trust, confidence, and satisfaction; brands; and financial risk. This includes learning how to adapt top team behaviour and motivation to act and create a CSR orientation in the firm. This requires developing CSR dimensions to leadership capabilities, skill sets, mindsets, beliefs, and attitudes

In this respect, many practitioners have argued (Ethical Finance Conferences, 2018 to 2021) that boards must select diverse executive teams and leaders with the capabilities to promote this CSR oriented and holistic, forward-looking view of the firm to middle management and front-line employees. They must ensure they have capabilities to understand views at these decision levels and show they have listened and adapted their policies accordingly. They include learning how top teams can create a 'tone from the top' to improve awareness of CSR oriented behaviour expected in the firm.

These above CSR changes to top teams or 'Heads' are the basis to make strategic choices about CSR purpose and orientation of the firm, and desired CSR outcomes. Given CSR change pressures, such diverse boards with clear CSR purpose, and explicit performance metrics, are expected to improve performance - CSR and financial - and the quality of CSR reporting. This reflects findings in the literature. by Birindelli et al, (2018, 2019); Jizi et al (2013); and Kilic et al (2015). Change in top team CSR oriented areas such as, gender and knowledge diversity of leaders and in boards of banks is associated with environmental performance (Birindelli et al, 2018, 2019; Deloitte, 2020). Jizi et al (2013) found evidence that US bank board independence and board size, the two board governance characteristics 'usually associated with the protection of shareholder interests, are positively related to CSR disclosures'. Kilic et al (2015) found that CSR reporting of banks improved during 2008 to 2112, and this was associated with size, ownership diffusion, board composition and board diversity. 


\section{2 Creating organisational conditions to change behaviour for CSR aims}

The second part of the change narrative discusses CSR change themes identified in three critical areas within the 'House' metaphor. These include CSR oriented changes to firm organisation and knowledge resources, control and influence mechanisms, and to technology. This involves CSR oriented changes to the 'socio-technical' context (Mumford, 2000; Mitleton-Kelly, 2003) and the way its influences use of financial resources. The case financial firms learn and explore how combinations of these intangibles and tangibles can be adapted for CSR aims and integrated in financial firm business models and value creation chains (IIRC, 2013). These changes are strategically matched to changes in the external environment (Teece et al., 1997) concerning CSR pressures and climate change and the need to develop resilience in the face of uncertainty.

These strategic decision choices are central to the development of CSR sensitive intangibles (internal, external social structures, and knowledge) and control systems in the organisation. They are critical to their combined role in mobilising intangibles and directing CSR oriented behaviour in other employees, to create information in the financial firm, and make financial transactions possible. These choices help create a positive CSR 'atmosphere' in organisational conditions and their influence on employee behaviour and in interactions with customers.

Thus, practitioners recognise that deep rooted CSR orientation must be achieved in organisational factors and their connections and influence on individuals and teams. They appreciate that influence of the formal CSR policy must be continuously supported and strengthened from top teams down to front line employees, whilst maintaining the financial orientation and function of the firm. Top teams in case firms such as NatWest (Rose, 2020), and Schroders (Harrison, 2020) are making it clear that key organisational factors: such as authority roles and power in the hierarchy, control systems, culture, feedback systems, and incentives; must have a clear and explicit CSR orientation. Top teams are using these combined organisational factors to build individual employee and team understanding and commitment and ensure employee conduct with customers is consistent with formal CSR policies of the firm.

In addition, board and executive top teams in these case firm understand how CSR and CC aims can be built into activities at all levels in the firm and business model. These top teams are developing an explicit holistic or systems view of the firm, and its role in financial markets, the real economy and society. They are communicating this 'integrated thinking' (IIRC, 2013; VRF, 2021) about the firm to employees at all levels within the firm.

\section{Adapt intangibles to be CSR oriented}

Internal intangibles include factors such as Culture, Organisation, and Knowledge. They include employee trust and belief in top teams, commitment to financial firm aims, and motivation to act in the desired ways to achieve CSR and financial aims (Holland, 2016). External intangibles include factors such as customer relations, brand, reputation and trust with customers and other external stakeholders (Chen et al, 2014).

As noted above, formal learning capabilities and active learning create understanding for top teams, when making strategic choices in a financial firm about individual social and knowledge factors and their positive and negative connections and interactions. They are the basis to make choices about these intangibles in their integrated business model (IIRC, 2013) so that; they are responsive to CSR and climate change issues but maintain the core function of transforming financial resources and risks for customers. They are means to develop the intangibles, so they have capabilities to influence agent behaviour and actions, in the firm and with customers (in value creation processes), to achieve CSR aims as well as financial aims.

Knowledge resources include intellectual capital (IC) (Meritum, 2002) about knowledge and capabilities of teams and individuals (human capital). They involve knowledge of financial needs of customers, of financial 
transactions, and financial markets. They comprise financial expertise (Preda, 2005) and understanding of the role of social intangibles such as brand, reputation, and customer relations in supporting transactions in markets. They include knowledge of financial intermediation and risk management at financial portfolio (asset, liability) and financial firm level (Lewis and Davies,1987). Such knowledge resources created the capability for agents to act in financial firms and in external social contexts concerning customers in markets.

There are strong pressures to develop the CSR dimension to such knowledge resources. For example, BNY Mellon (2017) noted that in 2017 the Comptroller of The City of New York sent letters to companies,

'requesting board member skills and attributes laid out in a matrix so they could assess a wide range of issues such as Board gender, racial and ethnic diversity, need for refreshment, and skills needed. Although we did not receive such a letter, we took steps to provide a skills and attributes matrix in our 2018 proxy statement'.

And

'Diverse and inclusive companies tend to encourage out-of-the-box thinking, provide opportunities for continuous learning and value unique skills and experiences. They treat people with fairness and dignity, respect individual cultures and needs and want employees to bring their whole selves to work for maximum positive impact',

Social resources concern social structures such as financial firm organisational structure and control systems as well as external networks. The latter include relations with customers, shareholders, and stakeholders and other financial firms concerned about CSR and climate change issues. Culture is an important attribute of organisation (Schein, 1984). Social resources also include agent knowledge of social structures such as structural capital about organisation, and relational capital about networks (Meritum, 2002).

The history of financial firm development during major external change has shown how firms adapted to survive. This required strategic re-organisation and redesign of functions in financial firms, around new markets for customer needs, financial products, transactions and services. Examples of such change occurred with Universal Banks in 1980-2006 (Holland, 2010) when they combined commercial and investment banks. In a world of CSR change pressures and climate change, major commercial banks such as RBS and ProCredit Bank are now learning how to re-organize firm structure and control systems around new CSR and 'green' oriented customers, financial markets, and products (RBS, 2014,2018; ProCredit Bank, 2016).

As noted previously a key organisational change at the top involves creating specialist board committees dedicated to addressing CSR issues. This also requires new ways of top team thinking about CSR. It involves using this to consider how to re-organise risk management, control systems, learning processes, team structures and decision routines, around CSR issues. It involves using these mechanism and structures to influence employee behaviour to be CSR oriented.

Technology based control systems such as Schroders (2019) 'SustainEx' are designed to measure costs and benefits of social and environmental action. These bring CSR issues and information to bear on decisions about individual financial transactions by front line teams, in specialist financial portfolio decisions by middle management, and firm wide financial decisions by top teams. These connected social and technology resources and their mobilisation contribute to social forces which drive agent and team action in the financial firm relative to financial, CSR and climate change aims. This reflect Silverman's (1970) view that social reality is socially constructed, socially sustained, and socially changed.

The CSR oriented organisational change, technology and control system changes, together act as a new frame to interpret organisational meanings and actions by top teams and employees in the firm. Perrini and Vurro (2010) argue that new ideas of corporate sustainability and responsibility have,

' an impact on organizational capital accumulation, being an important source of fundamental changes in business philosophy, decision-making criteria, and ways of working together' and by '.....addressing internal organization may have 
an impact on symbolic capital accumulation, aligning organizational member behaviour with stakeholder expectations and enhancing corporate reputation as a reliable partner'.

The above strategic choices about organisation, technology and control are designed to create a sustainable competitive advantage (SCA) unique to each financial firm (Barney, 1991; Teece et al, 1997). The SCA is the basis to create power and influence, knowledge, and transactional advantages over customers. It is a basis to use these advantages to influence their financial transacting behaviour with customers to reflect complementary CSR and financial aims. It is basis for top teams to create power over and hierarchical relations with employees to influence their behaviour in the firm to reflect these aims. These are expected to be the basis for financial winners and losers to emerge in banks and other financial firms concerning combined CSR and financial aims. They are expected to be the basis for the financial firm to deliver coherent CSR and climate change outcomes desired by stakeholders.

\subsection{CSR changes in 'Community' values, experiences, and behavior.}

The third part of the change narrative discusses CSR change themes identified in critical areas within the 'Community' metaphor. This focuses on direct means for the promotion of CSR awareness and the pro-active use of firm wide interactions to ensure all major finance decisions are 'CSR aware'. The CSR awareness activities involve engagement, learning, use of good practice and culture, and self-monitoring. The CSR awareness activities and interactions combine with contextual influences (from Head and House) to focus employee minds on how CSR aims can be incorporated with financial aims at the point of financial decisions. Engagement with customers reflects all these influences.

This metaphor provides insights into the 'lived experience' or 'life' of employees, customers and stakeholders involved in CSR change in behaviour in internal and external 'communities' or social organisations. It highlights the main factors at play and their connections in the CSR change process in the 'community'. It illustrates how they generate social forces (Silverman, 1970; Bourdieu, 1990) to change behaviour and financial decision practice in the firm and with customers.

The 'community' raised awareness states and contexts change together in in mutual reciprocal influences, activities, and interactions. They generate social forces to promote CSR change processes in behaviour in communities in the firm and external network. They change employee work conditions, experiences, values and behaviour throughout the firm organisation, and external networks. They change the 'lived experience' and behaviour of individual employees and teams in the firm and external communities, when interacting with each other and with customers and other stakeholders. They change the financial decision practices in the firm.

Case firms such as NatWest and Schroders use the above dynamics to enhance employee confidence in new CSR aims and CSR oriented structures and capabilities. They seek to enhance employee - trust and belief in top teams, commitment to financial firm aims, and motivation to act in the desired ways to achieve CSR and financial aims (Rose,2020, Harrison, 2020). They use change in employee CSR behaviour to build trust with customers and develop a CSR orientation to intangibles such as relations, brand, reputation with customers and other external stakeholders. They create a learning and behaving cycle between employees, customers, and stakeholders in which there was no end (Vaccoro, 2019).

These changes are expected to improve individual and team performance, customer relations, and firm performance. In this regard, Esteban-Sanchez et al (2017) found that during and after the financial crisis (20052010) banks with better employee relations and corporate governance had better corporate financial performance. 
During the crisis, better relations between employees and the community were valued positively by investors, which, in turn, increased corporate financial performance.

Thus, the third part of the strategic empirical 'change narrative' concerns core dynamics in the CSR change process in the 'community'. This involves many interactions and 'lived experiences' by individuals and teams in increasingly CSR oriented 'communities' in the firm social field and external network social field.

These connected contextual social resources and knowledge of these, their mobilisation, and direct CSR awareness activities collectively contribute to social forces which drive agent and team financial decision action in the financial firm and networks relative to financial, CSR and climate change aims. This reflects Silverman's (1970) view that social reality is socially constructed, socially sustained, and socially changed. In Bourdieu's (1990) terms the CSR awareness activities and interactions, within field context, are combined means to structure habitus, expertise, and social and symbolic capitals in new CSR oriented ways. They structure 'Head', House' and 'Community' and their impact on decisions in the financial 'Machine'.

\section{The 'lived experience of CSR change in the 'Community'}

This subsection section provides insights into the 'lived experience' of employees, customers and stakeholders involved in CSR change in behaviour in the 'community'. It uses a range of - CSR awareness activities -to illustrate how firm employ dynamics - between context, resources, and social interactions- in this CSR change process.

The CSR awareness activities included: Engagement about CSR issues; Learning and acquiring CSR knowledge (internal, external); Exchange of good practice; Embedding values and culture; and Self-monitoring and discipline. These are a basis to improve customer and employee experiences. These CSR awareness activities focus on employees, customers, and stakeholders.

\section{Continuous engagement}

In case financial firms, continuous engagement throughout internal and external communities occurs during the CSR change process. Engagement in community is a means to bring CSR adapted firm wide context and intangible resources (Head and House) directly to bear on the CSR change. It concentrates on how to alter employee mindsets and the ways the firm employees behaved and delivered core financial products and functions to customers and stakeholders. Engagement and discussion activities are done throughout the firm and with customers and stakeholders.

Practitioners such as Rice (2019) and Cuthbert (2019) note that boards and executive teams have extensive discussions on how to develop CSR engagement in the firm. CSR engagement, debate and discussion is done in all teams, financial decision activities and levels. This ranges from: top executive teams dealing with financial risk management across the whole firm, middle management dealing with specialist financial asset and liability portfolios, to front line teams dealing with individual financial transactions with customers. CSR values and aims are directly discussed and debated with financial values and decisions at the point of decisions being made in specialist teams, with a view to creating complementary CSR and financial outcomes.

Hayhoe (2021) argues that such CSR awareness raising and persuading activities, are best done by working from existing values, norms, and experiences of employees in firms and their customers and stakeholders. This requires less emphasis on guilt and overloading people with facts, and more emphasis on active discussion on the common ground for change in areas such as CSR and climate change. Discussion within these groups, of how their immediate experience of specific CSR problems has had a negative impact on them, is more likely to open the wider debate. Matching and tailoring the conversation and debate to the special position of others is more likely to be successful. 
This involves matching CSR communications and argument to existing values and norms in the firm and external networks. These include working from culture in the firm (Schein 1984; Harrison, 2020), secular belief systems and new CSR norms in society (Dashwood, 2020), specific aspects of faith-based beliefs (Haresnape.2019), and common principles of responsible behaviour agreed for a finance sector such as banking (PRB, 2018). It requires working forward from that starting position to more expansive ideas of what these groups can do about wider CSR aims/

Thus, engagement and debate between employees, in all key decision teams and at different hierarchy levels for decision making, is essential to change mindsets and working conditions in the whole firm. These multidimensional interactions are required to ensure that the implementation of CSR and CC policies is consistent throughout the firm in financial decision activities at each level and specialist team.

For example, Rice (2019) argued that engagement between employees on CSR and Climate change concerns is vital. Each firm must have a continuous exchange of views between employees about desired behavior in 'financial decision activities' such as lending and other individual transactions, as well as in financial risk management for specialist portfolios or businesses, and the whole firm. They must have a continuous discussion and analysis focused on how 'financial decision-making activities' can be oriented to CSR concerns as well as to conventional financial aims. The discussion must include how existing (actual not idealized view of) intangible resource factors in the firm such as culture, incentives, control systems, and specialist expertise, have historically been focused on sales growth and financial aims They must discuss how this acted as a barrier to desired change and how CSR oriented change must be made in these factors.

Cuthbert (2019) of the CBI argued that banking professionals required clear understanding of recently created ethical standards or codes in banking (CBI, 2018). They needed an ethical sensitivity or knowledge to know that they were facing an ethical problem in their financial decision activity and work. Priest (2019) of NatWest argued that such professional codes had to be simple and clear and easily understood so that top teams and employees in banks knew where the ethical lines were. Staff required time to pause and reflect during financial decision activities. Ethical training was needed to help them think about the ethical issues and consequences of decisions.

\section{Continuous learning}

As noted in previous sections, continuous learning arose in interactions in internal and external communities (Pedler et al 1997) during the CSR change process. This learning was required to develop CSR oriented knowledge at top, middle, and front-line employee levels, and during interactions with customers and stakeholders. In Meritum terms (2002) this involved creating and sharing new intellectual capital or shared knowledge as social and relational capital, and as individual expertise or human capital.

Hibbert (2019) of ING bank argued that top team learning about CSR in networks of banks speeded up the change process. He was heavily involved with international banks developing the UN 'Principles of Responsible Banking' (PRB, 2018) on behalf of UNEP. This was key to learning about responsible banking from others and contributing from ING's experience. This learning was supported by practitioner debates such as Ethical Finance (2018 to 2021), Green Finance (2018to 2021). These promoted learning by all employees in financial firms on CSR issues.

Learning creates new context and intangible resources to influence behaviour during interactions. These are mean to create information and enhance employee financial decisions. They are also means to develop more CSR sensitive policies with customers. These experiences are key to continued learning.

In the first case, the CSR oriented intangibles and technology are mobilised and used to develop 'soft' and 'hard' information (Chen et al 2014; Holland, 2016); about external change from CSR issues, the finance system and real 
economy, and from immediate opportunities. This information is the basis to support CSR oriented financial decisions at transaction, portfolio, and financial firm levels. It is used to enhance the production and sale of the CSR oriented products to customers (Chen et al 2014; Holland, 2016) through CSR sensitive channels.

In the second case, this involves situations where firm employees are sensitive to customer concerns and views and are not just pursuing the 'bottom line'. Using CSR oriented behaviour to improve ccustomer relations and to enhance trust and reputation, can create conditions required to transact in new types of investment and financing products and services. In banks, this includes maintaining bank branches and ATMs where there are many vulnerable customers. This concerns the bank avoiding the transfer of 'digital' risk to customer (error, fraud, tech failure etc) to customers by continuous complex product and technology change. This contradicts the core function of financial firms of managing risk for many customers.

Transferring digital and knowledge risk to customers can increase financial risk for customers and ultimately the financial firm. Avoiding this can reduce the adverse effects of bank and customer behaviour on financial risk and financial intermediation. This illustrates how a financial firm can critically reflect and learn how to manage these issues so that its behaviour and actions reflect a complementary approach to financial and CSR aims.

Triodos bank, is a signatory to PRB (2018) and long-time advocate of responsible banking. The bank has an active approach to learning at all levels in the bank community. Vaccoro (2019) that learning about CSR in Triodos bank and by customers and stakeholders was enhanced by various means. For example, the UNEP SDGs provided a coherent vision for thinking about change in the firm and with customers. Triodos also put all their loans on their web site for public viewing. In 2019 they implemented a 21-factor analysis of lending which contained many CSR criteria as shared human and structural capital in the firm (Meritum, 2002). They used these approaches to create new conversations and connections with customers on CSR and climate change. This helped them to find new areas where CSR (and CC) oriented finance could flow. They discovered new financing opportunities: in say, company supply chains, production, and sale activities; by discussing alternative CSR (and $\mathrm{CC}$ ) oriented ways of doing these activities.

They used their expertise in the latter areas to engage with and point companies in new directions. They shared best CSR and CC practice with client firms and used this to nudge customer behaviour and economic activity in directions that satisfy Triodos's lending criteria. As a result, they aligned their lending book with CSR principles such as the PRB and with climate changes aims such as the Paris (2015) agreement. For example, they moved out of financing firms involved - in the exploitation of labour in supply chains - and in mining and use of coal.

This two-way learning and interactions with customers were the basis to codify internal practice and create new knowledge with, and for, employees. Dissemination of this knowledge through employee training ensured consistency throughout Triodos and when dealing with customers. Triodos found the PRB (UNEP, 2019) a useful but general guide. They preferred to focus on their own more detailed and tailored approach to closely match their philosophy (see Triodos Bank Report 2015, p8). The bank focused on what they learnt about customers and themselves. They created a learning cycle between employees and with customers in which there was no end (Vaccoro, 2019). Such knowledge creation led to high internal and external sharing of ideas and of influence throughout the firm and with customers.

\section{Exchange of good practice for financial decisions}

CSR change also required a regular exchange of good practice and active training. Case such as Triodos, sector guidance such as the PRB, and various practitioner events (Ethical and Green Finance), provide examples, 
tested knowledge and ideas for less sophisticated banks to develop in their response to CSR change. These stimulate learning in 'novice' banks on how they can change their many organizational factors, top team capabilities and tone from the top. These can inform employee financial decisions activities to be more CSR oriented. Practitioners such as Cuthbert (2019) and Priest (2019) argued these CSR awareness sources and activities were means to train employees and influence their mindsets and attitudes, and to incentivise their behaviour during financial decisions and interactions with customers. They acted in support of formal CSR aims, embedded CSR beliefs and CSR oriented organizational contextual factors - to influence employee behaviour. The expectation was that the more explicit and vigorous the use of CSR awareness activities by top teams with employees, the more likely that individual employees and teams would be directly influenced and motivated in their financial decision activities with customers.

\section{Culture and embedding values}

Culture is an important socially embedded part of the organization's influence and informal control system (Schein, 1984; ACCA, 2014). It combines with formal control systems and their technology capabilities, and CSR oriented incentives, to control behaviour. These are the collective means to control bias and manipulation in employee decisions, behaviour and in financial reporting (Steer, 2018), and other behavior at odds with financial aims (value, risk), and CSR and sustainability aims

In the case financial firms, during the CSR change process, it was necessary to embed CSR oriented values and culture in financial decision activities. Faith based financial firms, with their explicit ethical stance and values provide a valuable and visible means to see how this can be done.

The approach of banks such as Gatehouse and Chief executive Charles Haresnape (2019), involved using faithbased values and culture, incentives, and other means to develop employee commitment and motivation. They create a good working environment for all staff to build culture, mindsets, values, and desired behaviors in financial decision activities. This approach is a convenient model for bankers to learn about how to develop their own bank specific ideas.

Gatehouse concentrated on the ethics of lending to achieve CSR outcomes by employees transacting with relationship customers. The aim was to make a difference to customers in terms of, delivery of financial services, and transactions that were priced in socially responsible ways. They aimed to make difference to employees in terms good working conditions, stable work contracts with competitive pay, and in terms of job satisfaction. Gatehouse learnt how to develop incentives to match their values and promote an ethically oriented culture. They engaged with employees over time to discuss these issues and develop incentives in a co-operative way. The result was an incentive scheme that is based on 50:50 split between desired financial and ethical outcomes. The ethical outcomes were assessed first and financial outcomes second. If behaviour by employees was acceptable then financial outcomes were assessed and if positive, they were used in bonus calculations. Bonuses still existed because this was the norm of wider 'finance society'. To ignore this would seriously affect the quality of employee human capital recruited to and staying with the firm. Gatehouse sought to embed these ideas of incentives throughout the firm. Committed staff then played an active role in weeding out those who were not performing ethically with customers and with other employees.

\section{Continuous observation, self-regulation}

As noted above, continuous observation, self-regulation and discipline of conduct and behaviour was required between employees and with customers during the CSR change process. Within the firm community this required 
a challenge and reflective culture during decision and policy implementation activities at all levels from the board, executive teams, middle managers, and front-line teams. When this failed a robust whistle blowing system was required.

Priest (2019) provided more insight into self-regulation and self-discipline activities within NatWest bank. Top teams and middle management and other employees were engaged in discussing and agreeing ethical standards (as a form of Structural Capital, Meritum, 2002). They discussed and agreed on how this changed incentives and expected behaviour with each other and with customers.

This high awareness and understanding by NatWest employees meant there was a natural social control in the firm and with customers. Employees shared mindsets, when operating in teams, and in connected hierarchical levels, were partially visible. They observed each other through a lens of desired ethical behaviour. They discussed and voted on actual and proposed decisions made by teams and individuals. It was in their own interest to discipline each other and exercise control over behaviour between employees and with customers which at times was secret, and difficult to observe. Thus, there was an explicit attempt to monitor the change in ethical environment (Bobek et al, 2015) for all employees and their CSR awareness and motivation.

This use of social controls maintained and built the culture, values and mindsets shared between employees. This form of engagement and self-discipline was repeated with customers and stakeholders by informing these agents what the bank will do with employees who crossed ethical red lines. This helped to build relationships, trust, and reputation (and brand) with customers.

\subsection{Changing financial decisions and the financial 'machine' to be CSR oriented}

The fourth part of the change narrative discusses CSR change themes identified in the financial 'Machine' metaphor. The change themes concern CSR changes to financial decisions, especially their structure, processes, and outcomes.

Morgan (p6, 1997) notes that when 'managers think of organisations as machines they tend to manage and design them as machines made up of interlocking parts that each play a clearly defined role in the functioning of the whole'. The financial firm 'Machine' is seen in finance theory as a financial decision and finance transformation means. It is made up of highly structured and connected financial decisions about: transactions in front line teams; specialist financial portfolios by middle management; and firm wide financial decisions by top teams (capital structure, mix of portfolios and products etc). These are the collective basis to financially intermediate or transform risk, return, maturity, and size of input capital into desired capital outputs for customers and economy (Scholtens and van Wensveen, 2003). The 'machine' is thus at the heart of core financial functions in the economy.

This 'machine' metaphor as theory of financial intermediation (Lewis and Davies, 1987) is a convenient abstraction to create valuable insights. However, the GFC in 2007-08 has shown (Holland, 2010) how this metaphor, has major problems especially when finance theory, based on logic, dominates human and CSR aspects. Morgan argues (1997, P5) the 'Machine' metaphor is incomplete, ignores human aspects, is biased, and elevates rationality. It is misleading as the 'organization is not a machine and can never really be designed, structured, and controlled as a set of inanimate parts' and ....'the challenge is to become skilled in the art of using metaphor: to find fresh ways of seeing, understanding, and shaping the situations that we want to organize and manage'.

This paper adopts this approach by using metaphors of 'Head', 'House', and 'Community' to outline the human or non-financial dimensions to financial firms. Their relationship to the financial 'Machine' is made explicit by viewing the firm as a unique social and economic system (Mumford, 2000). The financial machine operates in wider social or nonfinancial context. The set of integrated metaphors 'offers ways of thinking that is crucial for understanding, managing, and designing organisations in a changing world' (Morgan, 1997, p8). In the paper, the metaphors are connected in one interacting financial firm system and discussed using theory. 
This integrated non-financial social system and financial 'Machine' are designed to jointly guide CSR oriented financial decisions and manage risk during financial intermediation (Lewis and Davies, 1987). They are intended to jointly produce and deliver outcomes such as CSR oriented financial products and desirable CSR outcomes amongst employees, customers, and other stakeholders. This is the means to deliver complementary CSR and financial aims. Thus, the financial function remains central but is adapted by the non-financial context to reflect CSR concerns.

This sub section focuses on the collective impact of 'Head' and 'House', and 'Community' on financial decisions and associated structure, process, and outcome elements of the financial 'Machine'. They influence the social structure, purpose, values, and 'atmosphere' of the financial 'Machine'. They influence a hierarchy of decisions in the firm (single, portfolio, firm wide), as well as decision routines used in all these hierarchy levels. This includes CSR oriented financial strategy of the whole firm by top teams, and specialist financial portfolio management) by middle management. It includes specialist single transaction decisions by front line teams. All of these are supported by back-office teams.

This reveals how the non-financial context influence the financial intermediation processes, and the CSR oriented outcomes of the use of financial resources. This highlights the main factors at play and their connections in CSR change in the financial 'Machine'. It concerns how they change financial decision behaviour and practice in the firm and with customers. This collective system change is means to ensure there are many internal firm CSR pressure points - policy, culture, teams etc - at the point of financial decision making. This prevents falling back into traditional finance logic alone. All teams must adopt CSR values and aims and use them in complementary ways with finance values and decision logic in everyday financial decisions.

Both finance theory (Lewis and Davies, 1987) and behavioural finance theory (Statman, 1999) are used to analyse the CSR oriented changes to use of financial resources in the financial decision 'Machine'.

\section{Case examples how non-financial contexts effects the financial 'Machine'}

The financial firm cases and debate at practitioner events such as Ethical Finance (2018-2021), illustrated many insights on how the non-financial context and CSR awareness activities influence the financial 'Machine'. For example, Rice (2019) of BSB argued that engagement between employees on CSR (and climate change) concerns was vital. Each firm must have a continuous exchange of views between employees about desired CSR oriented behavior and information required in 'financial decision activities' such as lending and other individual transactions, as well as in financial risk management for specialist businesses, and the whole firm. They must have a continuous discussion and analysis focused on how 'financial decision-making activities' are oriented to CSR concerns as well as to conventional financial aims.

The case financial firms recognize that discussion must include how factors in the firm such as culture, incentives, control systems, and specialist expertise, reflect the new priorities chosen between CSR, sales growth, and financial aims. They must avoid historic errors of focusing on sales growth and financial aims alone and creating barriers to desired CSR change.

In the case firms, financial decision activities occur in specialist financial decision routines at top team, middle management, and front-line teams. The routines include various phases such as 'Search, Analyse, Value, Transact/not transact, Monitor, Complete or exit from single or portfolio transactions' (Holland et al, 2012; Chen et al, 2018). Teams in case firms, at all levels, discuss how the relative priorities of CSR, sales growth, and financial aims are reflected in all phases of financial decision routines, based on explicit firm wide purpose. The aim is to create a CSR orientation and bring to bear CSR values and information about CSR costs and benefits in each decision phase, and hence influence all aspects of financial decisions. 
In more specific terms, knowledge intangibles such as financial expertise (product, and analysis) and new forms of CSR expertise are used in the case firms to create information in decision routines for activities such as making decisions about financial transactions, and portfolios at specialist product level (say loans, and for all financial assets and liabilities in the firm. The CSR values, CSR modified behavior and new information are the basis to create financial value and manage risk. They are means to deliver coherent CSR policies leading to desirable outcomes required by stakeholders.

The use of technology to develop and communicate information about CSR costs and benefits, combined with continuous communication of CSR values, plays a role in all phases of decision routines from initial search to final decision (Harrison, 2020). This is the basis to deliver financial products to customers and transform financial capital and its risks in wider financial intermediation processes relative to CSR and financial aims.

Within the decision routines, information collection and use were monitored for CSR risk. For example, case banks required information about the potential impact of loans in food production which encourages obesity. Insurance firms required information about CSR risks and subsequent financial risks faced by the insured firm customer using fleets of diesel cars. Fund managers required insights into CSR risks faced by investee companies misusing social media data about their customers. They required information about CSR issues faced by investee companies with employees and their supply chains.

In more specific terms front line teams in case financial firms (Ethical Finance, 2018-2021), actively engage with customers explaining policies such as withdrawal of financing when faced with negative CSR behaviour at odds with principles of responsible financial transacting as defined in PRB, PRI, PSI. They make it clear to corporate customers they will only provide for debt or equity finance for positive CSR oriented purpose in say supply chain, production, marketing and selling. They explain how they design debt terms for these customers, by adding covenants whereby customers must achieve CSR performance metrics by set times or the debt defaults.

The front-line teams in case financial firms monitor customers to ensure they do not arbitrage between parts of the firm with different CSR approaches. This involves customers switching from loans to say bonds within a bank due to variation on CSR demands. The financial firms look at each transaction within the context of their CSR policy, CSR incentives and finance incentives, CSR costs and benefits of the deal, and customer relations. They use this holistic view to prevent negative consequences across the bank within firm and with customers.

Financial firms also seek to change collective customers mindset and behaviour by active CSR engagement over many years. They do this collectively say in the bank industry - by setting common agreed CSR performance policies and metrics (for the financial firm and customers) and communicating this to all customers in CSR sensitive industry sectors. Thus, they seek to prevent negative consequences of customers arbitraging on differing CSR policies across banks and thus transferring the CSR problem rather than reducing problems.

In all the above a CSR firm wide framework in the case financial firms is a means to set these issues in context and guide integrated thinking on behaviour and actions. This reflects the increased desire of financial firms to bring to bear CSR oriented 'Head, House, and Community' on decisions. They bring policy, culture, incentives, knowledge, control system, cost/benefits etc; to the point of financial decision making by front line teams (transactions), middle management (portfolios), and top teams (whole firm finances).

Theory analysis

The case firms illustrate how CSR oriented organisational means, collaboration, and competitive advantages are means to overcome major behavioural and informational problems, to deliver innovative financial services for CSR 
outcomes as the priority. They seek to generate superior financial performance consistent with these CSR aims. This approach when applied in individual firms and in a collaborative way across a financial community (say banking) are means to reduce behavioural and information problems.

The social and economic changes at firm and sector levels are part of a 'values' strategy to change norms, beliefs and behaviour to reflect CSR aims. This approach when applied in individual firms and in a collaborative way across a financial community, are means to reduce major information asymmetries and transaction costs associated with CSR change pressures and risks, between financial firms, and between them and their customers and stakeholders.

The impact on financial decisions from CSR change in the financial 'Machine' can be analysed from a behavioural finance theory perspective. Statman (1999) review indicates that the case financial firms seek to use their new CSR context, process, and capabilities to reduce behavioural biases (say optimism, confirmation) in firm employees and their teams when making decisions with customers in markets. These biases can subvert and undermine behaviour (Holland, 2016) consistent with CSR aims, and financial value aims. Given CSR change pressures, the case firms use 'Head, House and Community' to exercise control over their tendencies to exploit behavioural biases in others that lead to increasingly negative CSR outcomes for the firm and stakeholders.

This analysis reflects Hirshleifer's (2015) argument that there is a need to move from behavioural finance to social finance, including social norms in the study of financial behaviours. He notes 'Especially, the time has come to move beyond behavioral finance to social finance, which studies the structure of social interactions, how financial ideas spread and evolve, and how social processes affect financial outcomes '.

The impact on financial decisions from CSR change to structure and process in the financial 'Machine' can also be analysed from a finance theory perspective. The changes to 'soft' or non-financial infrastructure, and development of firm specific competitive advantages (Barny, 1999) within the agreed sector co-operative frames, are means to enhance finance decision conditions. These 'soft' changes support interpretation of stimuli, events, customer demand, market changes in financial decision routines. They reduce problems of information asymmetry, moral hazard, adverse selection in the firm, and transaction costs, between firm and customers, and with other stakeholders (Hefferman, 2005).

This creates capabilities and opportunities to source and allocate CSR oriented funds and make CSR oriented changes to the provision of 'hard' financial products and financial functions. These changes make CSR based transacting possible and improve the chances of success in transacting. This is repeated across many transactions and portfolios and in turn improves the chances of success in CSR oriented financial intermediation and in the management of CSR based financial risks in the whole financial firm (Scholtens and van Wensveen, 2003).

Information production about CSR issues in the cases reduce information asymmetry for financial firms about purely financial matters, and about CSR concerns. CSR information leads to decisions to avoid the transactions with problematic CSR dimensions. The same approach identifies financial transactions with more positive CSR outcomes.

The uses of organisational resources to avoid CSR problems and find new CSR opportunities are the basis to reduce transaction costs and enhance liquidity management, diversification, and risk management relative to financial and CSR aims. This creates conditions for transformation of financial capital and risks, to satisfy customer needs for financial services, and stakeholder needs for CSR outcomes. Hence the core function of the financial firm is sustained in the new CSR oriented world.

As a result, the financial firm mobilises CSR oriented 'organisation' and other non-financial intangibles, and promotes CSR awareness throughout the firm. It does this to support transformation of various forms of financial 
capital and their liquidity and risk characteristics in a CSR oriented financial intermediation process. It does this to achieve financial aims (value, risk) and aims concerning corporate social responsibility and climate change. Holland (2019a) noted that financial firms use intangible social and knowledge resources in the 'Head', 'House' and 'Community',

'to create information, control behaviour, and enhance decision conditions when exploiting financial resources. They mobilise intangible resources to reduce information asymmetry and transaction costs. They do this to enhance liquidity management, diversification, and risk management. This creates conditions for financial intermediation and hence the transformation of financial capital and its risks.'

\section{Discussion - Integrated thinking in CSR oriented firms}

This section argues that the CSR BTFF capability for integrated thinking is the basis to develop a set of integrated empirical and theoretical narratives about value creation and CSR in financial firms. This holistic narrative and metaphor approach is a means to answer the question, 'What is going on here?' and be able to 'stand back' and comprehend the bigger picture and central strategic issues when responding to uncertainty (Kay and King, 2020). The four-part metaphors and narrative aid comprehension of the whole financial firm system. Each metaphor provides insights into each key area and focusses attention on critical change factors.

This offers many opportunities for stakeholders. Management teams and employees can use this approach to support their implementation of a CSR change process. This firm can use this to think how to develop CSR reporting. Academics can use these ideas to develop theory and research on financial firms.

In the first case, the CSR BTFF indicates how the financial firm can be configured with 'integrated conditions'; or widely understood connections and interactions between resources, and the capabilities to exploit the connections and resources in financial decision activities; to achieve financial and CSR aims. Financial firms and other stakeholders can use the CSR BTFF as part of their specialist and unique firm 'knowledge of practice'. They use this within shared community-based knowledge and aims, and within legislation, as a basis for developing, a CSR oriented business, and creating financial value. Thus, the CSR BTTF framework can combine with legislative and collaborative frameworks for CSR, and with markets, to add momentum and coherence to the CSR change process.

In the second case, the CSR BTFF narratives, and ideas from the Integrated reporting framework (IIRC, 2013; VRF,2021) form an integrated thinking basis to think how to develop value creation and CSR reporting content for integrated reports or $<\mathrm{IRs}>$ in financial firms (Torre et al, 2018

CSR BTFF offers a complementary means to the $<$ IR $>$ framework to think how this can be done. The metaphors of 'Head', 'House', 'Community', and 'Machine' provide alternative but complementary means to think about CSR changes and their impact on the value creation processes embodied in the business model (IIRC, 2013; VRF, 2021). This supports a holistic view of firm and change processes to understand each element and how they work together. This forms a basis for coherent reports that can be effectively audited.

The CSR BTFF and narrative provide structure for forward looking reporting of content based on the structure of the business model. This can place scenario risk analysis of financial transactions and portfolios pursuing CSR change aims, in a meaningful context. Such improvement in disclosure is crucial to improving legitimacy of the financial firm (DiMaggio and Powell, 1991) with stakeholders (Guthrie and Parker, 1990).

The above reveals that the CSR BTTF provides a means to think what 'Relevant' or 'Material information' (p5, IIRC, 2013) may mean in financial firms in terms of the 'non-financial information directive' (EU, 2014; Baumuller, 2018). This can enhance the content of $<\mathrm{IR}>$ by showing connections between information on intangibles and financial resources. It can clarify how non-financial information about CSR is linked with 
financial information (Baumuller, 2018). These information outcomes are means to broaden understanding in the wider finance community and for this to be 'fully reflected' in informed valuations in financial markets. They are means to do the same in a much wider and critical stakeholder community. In both cases they are means to inform a consensus on whether the financial firm has delivered complementary CSR and financial outcomes and is not engaging in 'CSRwash'.

In the third case, the CSR BTFF does not seek to replace conventional finance theory. It seeks to complement such theory by connecting non-financial factors in the firm to financial factors (Holland, 2019a,b). It seeks to use the CSR BTFF and conventional theory as combined and supportive means to ask the question 'what is going on here' (Kay and King, 2020), when financial firms are becoming fully socially responsible.

This provides a context - four metaphors, their sub themes - and connections - as a way of framing change and debates about CSR change - within the firm - and externally with many stakeholders. It seeks to create a new conversation between many previously separated parties to exploit a diversity of minds and approaches in new more open research process between finance and non-finance academics (Holland, 2019b). This is a means to expand thinking and develop resilience relative to uncertainty created by ever increasing demands for corporate social responsibility in financial firms.

For example, this section argues that the CSR BTFF capability for integrated thinking is a basis for rethinking how CSR aspects of quantitative finance research can be rethought. The CSR BTFF indicates how quantified empirical tests can be designed to explore how financial firms adapt to reflect CSR demands. Clusters of cognate and associated variables are part of each key empirical theme or metaphor such as 'Head', 'House', 'Community' and' Machine'. The CSR BTFF shows how these interact in mutual, reciprocal interactions. It highlights the key variables in each empirical cluster and how they are associated in CSR change process.

This is a new basis for hypothesis generation and tests of such hypotheses. It could be hypothesised that the degree of achievement of CSR aims is a function of connected and combined changes in key variables in all of the empirical themes or metaphors. This firm-wide hypothesis (Poterba, 2021) of change in CSR oriented finance differs from conventional quantitative finance studies by its focus on the whole system rather than parts. For example, CSR BTFF could be used to hypothesize which factors are expected to predict 'success' as a CSR oriented financial firm. 'Success' - could be defined in many ways as ,

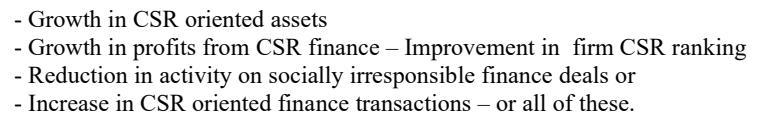

These measures of 'successes' could be hypothesised as being associated with CSR changes in:

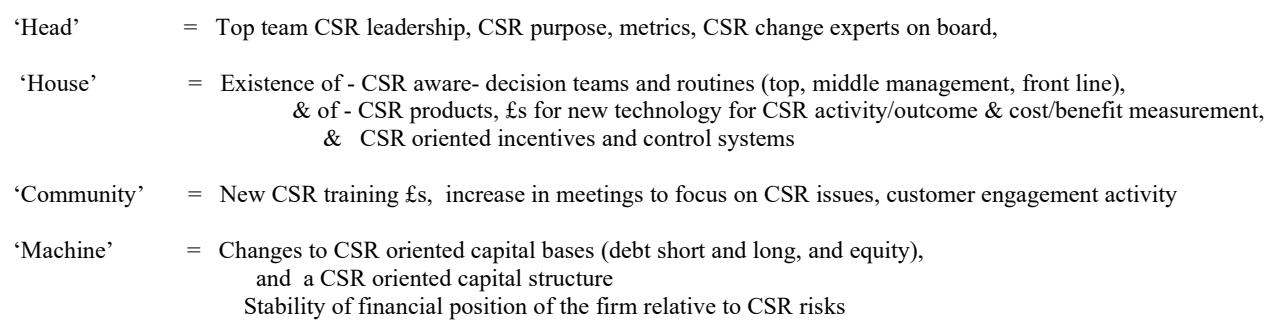

The above involves using the CSR BTFF to develop tests of the firm-wide hypothesis (Poterba, 2021) of change in CSR finance. This provides a coherent framework for meaningfully connecting a wider set of CSR firm variables such as in Buranatrakul et al (2017) or Raut et al (2017). The positive or negative role of factors in each metaphor area in CSR 'success' is a way to test for 'CSRwash' (Pope et al, 2016). The positive 
impact of factors in all areas would indicate systemic CSR change in the whole firm. This contrast with more conventional tests - connecting success to one or two firm variables - with these not being selected within a holistic conceptual frame such as the CSR BTFF. The paper argues that this will lead to testing of poorly connected or unconnected hypotheses. This fragmented approach may slow the development of academic knowledge about change in CSR finance.

\section{Summary}

The aim of the paper has been to answer the research question How can financial firms become CSR oriented? The paper noted problems in understanding CSR change in financial firms such as banks, insurance firms and fund managers (Chen et al 2014, 2019; Holland, 2010, 2017b, 2019a,b,c). The problems limited the development of integrated thinking (IIRC, 2013). This restricted management of CSR change, financial value creation, and the development of integrated reporting $(<\mathrm{IR}>$ ), in financial firms (Larsen et al, 2015, 2017).

The paper sought to answer research question and problems by using a new conceptual framework about financial firms or CSR oriented 'behavioural theory of the financial firm' (CSR BTFF) (Holland, 2017b, 2019a,b,c). This was based on empirical and theory narratives about CSR change in financial firms.

The CSR BTFF is a part of the means to answer the question, 'What is going on here?' and focusses attention on critical change factors (Kay and King, 2020. It forms a key part of a knowledge risk management strategy (Zack, 1999, La Torre, 2020) which directly addresses uncertainty and complexity by closing, in part, the knowledge gap (Holland, 2010) for academics and practitioners. It is part of the mean to close the 'values' gap arising by pursuit of shareholder wealth alone. The changes are part of the evolving set of means to realign value in financial markets with values of wider society (Carney, 2020).

This approach has potential 'to make a difference' in; researching, learning, thinking, and believing about desirable actions and responses to CSR problems and to demands for CSR oriented change in financial firms and wider systems (Shiller, 2019).

In the field of practice, the CSR BTTF has many potential uses 'to make a difference' in learning, thinking, discussions, and actions, by individual financial firms, and by co-operating and competing agents in the finance system and wider society. The agents include 'top teams', the rest of financial firm, advisory policy bodies, legislators, and regulators. They include civil society organisations (CSOs), customers, employees, citizens, and other stakeholders. The changes are part of the ways to align financial firms; their suppliers and users of funds (companies and customers); with CSR aims. These narratives also form a basis for firms and stakeholders to discuss how to improve non-financial reporting especially integrated reporting or $<\mathrm{IR}>$ (Torre et al, 2018). CSR BTFF offers a complementary means to work with the $<$ IR $>$ framework (VRF, 2021) to think how this can be done. Such improvement in disclosure is crucial to improving legitimacy of the financial firm (DiMaggio and Powell, 1991) with stakeholders (Guthrie and Parker, 1990).

In the field of academe this enhanced understanding can support development of an academic research programme about 'CSR oriented Finance' using a range of non-finance academic disciplines. It can encourage research in the field of finance (Gendron, \& Smith-Lacroix, 2013). The CSR BTFF also the basis to enhance collaboration amongst academics to critically analyse on how financial firms can and should become CSR oriented. This knowledge is intended to inform academic research, and for this to play a more active role in the practitioner debate. Thus, the CSR BTFF is part of an extended knowledge risk management strategy involving many wider system agents. 


\section{References.}

ACCA,(2014), ESRC and ACCA report (2014), “Culture and Channelling Corporate Behaviour: Summary of Findings" ACCA, 2014, available at; http://www.accaglobal.com/content/dam/acca/global/PDF-technical/corporate-governance/tech-tp-caccb.pdf

Age UK (2018), 'Age-friendly banking - What it is and how you do it'. https://www.ageuk.org.uk/Documents/EN-GB/For-professionals/Policy/money-matters/report_age_friendly_banking.pdf?dtrk=true

Anderson A, Wakamo B (2018), 'CEO-Worker Pay Ratios in the Banking Industry', Institute for Policy Studies (2018), https://inequality.org/wpcontent/uploads/2018/04/Bank-Pay-Ratios.pdf

Andrikopoulos, A., Samitas, A. and Bekiaris, M. (2014), "Corporate social responsibility reporting in financial institutions: evidence from Euronext", Research in International Business and Finance, Vol. 32, pp. 27-35.

Antonacopoulou E P (2006), 'The Relationship between Individual and Organizational Learning: New Evidence from Managerial Learning Practices ' 37; p 455 - 473 Management Learning

Arduini S (2021), Comment on - Holland J, 'A Knowledge Strategy for the 'Greening' of Financial Firms', paper presented at IFKAD, Uni Rome Tre, Rome Italy 1-3 September 2021 - Managing Knowledge in Uncertain Times

Avery H (2016), The collective struggle for better bank ethics, Euromoney Thursday, September 29, 2016

https://www.euromoney.com/article/b12kq31zwyy72x/the-collective-struggle-for-better-bank-ethics?copyrightInfo=true

Banking for Society (2012), What do we mean by corporate social responsibility and socially responsible banking? http://www.bankingforsociety.be/what-do-we-mean-corporate-social-responsibility-and-socially-responsible-banking

Barney, J. (1991). Firm resources and sustained competitive advantage. Journal of Management, 17(1), 99-120.

Baumuller J (2018), Materiality of nonfinancial information - How "integrated" are nonfinancial reporting requirements in accordance with Directive 2014/95/EU?, Intangibles and IC Conference, LMU, Munich Sept 20-21 2018

BCBS (2015), Basel Committee on Banking Supervision, Guidelines, ' Corporate governance principles for banks

Bebbington, J. (2008), Corporate social reporting and reputation risk management, Accounting, Auditing \& Accountability Journal, Vol. 21 , No. 3.

Bénabou R, Tirole J, 2006. "Incentives and Prosocial Behavior," American Economic Review, American Economic Association, vol. 96(5), pages 16521678, December

Belchambers A (2021) Day 3 City Week (2021) ‘Financing A Sustainable Global Recovery’, Wed Jun 23rd, 11th Annual International Financial Services Forum

Bihari, S.C. and Pradhan, S. (2011), “CSR and performance: the story of banks in India”, Journal of Transnational Management, Vol. 16 No. 1, pp. $20-35$.

Birindelli, G., Dell'Atti, S., Iannuzzi, A. and Savioli, M. (2018), "Composition and activity of the board of directors: impact on ESG performance in the banking system", Sustainability, Vol. 10 No. 12, 4699, doi: 10.3390/su10124699.

Birindelli, G., Iannuzzi, A.P. and Savioli, M. (2019), “The impact of women leaders on environmental performance: evidence on gender diversity in banks", Corporate Social Responsibility and Environmental Management, Vol. 26 No. 6, pp. 1485- 1499.

Bobek D, Hageman A, Radtke R (2015), ‘The Influence of Roles and Organizational Fit on Accounting Professionals' Perceptions of their Firms' Ethical Environment, J Bus Ethics (2015) 126:125-141

Bogan H, (2018), Head of professional standards, Chartered banking Institute (CBI), 'Sustainable solutions', Panel 2, 22nd Oct, 11.00-12.00 am, Ethical Finance Conference, 22nd-23rd October 2018, Edinburgh,

Bogan H, Robert Dellner, Charles Haresnape, Stewart Langdon, Rob Lake (2018); Discussion, Panel 2, 'Sustainable solutions', 22nd Oct, 11.00-12.00 am; Ethical Finance Conference, 22nd-23rd October 2018, Edinburgh

Bourdieu, P. (1990). The Logic of Practice. Cambridge, UK: Polity Press

Bratianu, C. (2020). A Knowledge Management Approach to Complex Crises. Management Dynamics in the Knowledge Economy. 8(4), 345-356, DOI 10.2478/mdke-2020-0022 ISSN: 2392-8042 (online)

Breeden S (2019), Bank of England, at Ethical Finance, Edinburgh, $8^{\text {th }}$ October, 2019.

Brunsson, N. (1989). The Organization of Hypocrisy Talk, Decisions, and Actions in Organizations. Chichester John Wiley \& Sons Inc.

BSB (2018), Annual Review 2017/2018

https://www.bankingstandardsboard.org.uk/pdf/banking-standards-annual-review-2017-2018.pdf

BNY Mellon (2017), Corporate Social Responsibility Report 2017,

https://www.bnymellon.com/us/en/ locale-assets/pdf/csr/2017-csr-report.pdf

Buallay, A. (2019), "Is sustainability reporting (ESG) associated with performance? Evidence from the European banking sector", Management of Environmental Quality, Vol. 30 No. 1, pp. 98-115.

Buranatrakul, T. and Swierczek, F.W. (2017), "Climate change strategic actions in the international banking industry", Global Business Review, Vol. 19 No. 1 , pp. 32-47

Carney M (2015), Breaking the Tragedy of the Horizon -climate change and financial stability, Speech given by Mark Carney, Governor of the Bank of England, Lloyd's of London29 September 2015

Carney M (2018), A Transition in Thinking and Action

https://www.bankofengland.co.uk/-/media/boe/files/speech/2018/a-transition-in-thinking-and-action-speech-by-mark-

carney.pdf?la=en\&hash=82F57A11AD2FAFD4E822C3B3F7E19BA23E98BF67

Carney, M (2020), 'How We Get What We Value', Reith Lecture, December 2020, BBC Radio 4 
Carroll, A.B. (1979). A three-dimensional conceptual model of corporate performance. The Academy of Marketing Review, 184, $497-505$.

Carroll, A. B., Shabana, Kareem M. (2010). The Business Case for Corporate Social Responsibility: A review of concepts. Research and Practice, International Journal of Management Reviews, 12(1): 85-105.

Carnevale, C., Mazzuca, M., \& Venturini, S. (2012). Corporate social reporting in European banks: the effects on firm market value, Corporate Social Responsibility and Environmental Management, 19, 159-177.

Carvalhal A, Dutordoir M, (2018), 'How Does the Governance of Banks Differ from Nonfinancial Firms? Evidence from Brazil', presentation at the 25th Annual Global Finance Conference, ESSCA, Paris, July 4th 2018

CBI (2018), The Chartered Banker Institute, https://www.charteredbanker.com/qualification/certificate-in-green-finance.html

Cuthbert G (2019) of the CBI (Chartered Bankers Institute), at the Ethical Finance Conference, Edinburgh, $8^{\text {th }}$ October 2019.

Chambers C, Day R, (2009), The Banking Sector and CSR: an unholy alliance?, Financial Regulation International, November 2009, Issue 12.9

Chen L, Danbolt J, Holland J (2014), Rethinking bank business models: the role of intangibles,

Accounting, Auditing, and Accountability Journal - Vol 27, Number 3, 2014 pp563-589

Chen, L., Danbolt, J. and Holland, J. (2018), 'Information about bank intangibles, analyst information intermediation, and the role of knowledge and social forces in the 'market for information', forthcoming in; Accounting Forum

$\operatorname{COM}(2011) 681$ Communication from the Commission to the European Parliament, the Council, the European Economic and Social Committee and the Committee of the Regions - A renewed EU strategy 2011-14 for Corporate Social Responsibility

Cornett, M.M., Erhemjamts, O. and Tehranian, H. (2016), "Greed or good deeds: an examination of the relation between corporate social responsibility and the financial performance of U.S. commercial banks around the financial crisis", Journal of Banking and Finance, Vol. 70, pp. 137-159

Cyert, Richard M., and James G. March 1963 A Behavioral Theory of the Firm. New York: Prentice-Hall

Daddi T, Todaro N M, Giacomo M R, Frey M, (2018, A Systematic Review of the Use of Organization and Management Theories in Climate Change Studies, Business Strategy and the Environment https://doi.org/10.1002/bse.2015

Dashwood H S (2020), The Rise of Corporate Social Responsibility as a Global Norm Informing the Practices of Economic Actors, Chapter 8 in H. Hansen-Magnusson \& A. Vetterlein (Eds.), The Rise of Responsibility in World Politics (pp. 167-187). Cambridge: Cambridge University Press. doi:10.1017/9781108867047.012

Dashwood H S (2012), CSR norms and organizational learning in the mining sector, Corporate Governance

De Bakker Frank, Andrew Crane, Irene Henriques, Bryan W. Husted, (editors), Publishing Interdisciplinary Research in Business \& Society, Business \& Society 2019, Vol. 58(3) 443-452

De Haan, J., Vlahu, R., 2016. Corporate governance of banks: a survey. Journal of Economic Surveys, v30, issue 2, April, $228-277$.

De Haan, J., Vlahu, R., 2016. Corporate governance of banks: a survey. Journal of Economic Surveys, v30, issue 2, April, $228-277$.

DiMaggio, J., Powell, W., (1991), “Introduction,” in W. W. Powell \& P. J. DiMaggio (Eds.), The new institutionalism in organizational analysis, Chicago Uni Press,

Donaldson, T., \& Preston, L.E. (1995). The Stakeholder Theory of the Corporation: Concepts, Evidence, and Implications. Academy of Management Review, 20(1), 65-91. doi: $\underline{10.2307 / 258887}$.

Esteban-Sanchez, P., Cuesta-Gonzalez, M.D.L. and Paredes-Gazquez, J.D. (2017), “Corporate social performance and its relation with corporate financial performance: international evidence in the banking industry", Journal of Cleaner Production, September 2017, Vol. 162, pp. 1102-1110.

Ethical Finance Conference (2018), 22nd-23rd October: 'Regaining Trust and Demonstrating Impact', Edinburgh;

Ethical Finance Conference (2019) , 8-9 ${ }^{\text {th }}$ October 2019; Edinburgh;

Ethical Finance Conference (2020), 5-8 ${ }^{\text {th }}$ October 2020; Edinburgh; Talk to Action,

EU (2018), "Financing a Sustainable European Economy", Final report of the High-Level Expert Group on Sustainable Finance, (31st January) available at: https://ec.europa.eu/info/publications/180131-sustainable-finance-report_en

EU (2009), European Union, Charter of Fundamental Rights of the European Union, https://www.refworld.org/docid/3ae6b3b70.html

EU (2011), European Commission, “A renewed EU strategy 2011-2014 for Corporate Social Responsibility”, available at: http://eur-lex.europa.eu/legal-content/EN/TXT/PDF/?uri=CELEX:52011DC0681\&from=EN

EU (2014), European Commission, Directive 2014/95/EU 'Disclosure of non-financial and diversity information by certain large undertakings and groups' https://eur-lex.europa.eu/legal-content/EN/TXT/?qid=1537870323040\&uri=CELEX:32014L0095

EU (2015), EU Payment Services Directive (PSDII), applied on 13 January 2018.

https://eur-lex.europa.eu/legal-content/EN/TXT/?uri=CELEX\%3A32015L2366

EU (2017) European Commission, 'Guidelines on disclosure of non-financial information’, Brussels, 26 June 2017, https://ec.europa.eu/transparency/regdoc/rep/3/2017/EN/C-2017-4234-F1-EN-MAIN-PART-1.PDF

European banking Federation (2008), Best practices for CSR,

https://www.ebf.eu/wp-content/uploads/2017/01/csr-2008-00975-01-E.pdf

Falkner R (2021), Environmentalism and Global International Society, Cambridge University Press, 2021,

Falkner, R. (2020). Global Environmental Responsibility in International Society. In H. Hansen-Magnusson \& A. Vetterlein (Eds.), The Rise of Responsibility in World Politics (pp. 101-124). Cambridge: Cambridge University Press. doi:10.1017/9781108867047.008

Fancy T (2021a), The Secret Diary of a 'Sustainable Investor', 20 Aug 2021, https://medium.com/@sosofancy/the-secret-diary-of-a-sustainable-investorpart-1-70b6987fa139 
Fancy T (2021b), Today Programme BBC Radio 4, $7^{\text {th }}$ Sep 2021, 7.20am-7.26 am, Tariq Fancy interview. https://www.bbc.co.uk/sounds/play/live:bbc radio fourfm

Flockhart C (2018), Director, Baillie Gifford, The United Nations SDGs as an investment theme. Practically...how? 23rd Oct, 9.30-10.30 am; Ethical Finance Conference, 22nd-23rd October 2018, Edinburgh,

FSB ( 2015), "Banking conduct and culture: A Call for Sustained and Comprehensive Reform”, July 2015

http://group30.org/images/uploads/publications/G30_BankingConductandCulture.pdf

FT Jan 12, 2016, Opinion FT View. "Culture is a matter for banks not UK regulators - FCA is right to focus on rules rather than minutiae of management"

Fatma M, Rahman Z, Khan I,; Multi-Item Stakeholder Based Scale to Measure CSR in the Banking Industry, International Strategic Management Review 2 (2014) 9-20

Favotto, A., \& Kollman, K. (2020). An Expanding Conception of Social Responsibility?: Of Global Norms and Changing Corporate Perceptions. In H. Hansen-Magnusson \& A. Vetterlein (Eds.), The Rise of Responsibility in World Politics (pp. 188-212). Cambridge: Cambridge University Press.

Fayad A A, Ayoub R, Ayoub M, (2017), Causal relationship between CSR and FB in banks, Arab Economic and Business Journal, 2 (2017), 93 - 98

FCA (2015), "Senior bank management held accountable in responsibility area", available at:

https://www.fca.org.uk/news/fca-publishes-final-rules-to-make-those-in-the-banking-sector-more-accountable

FCA (2021), Consumer Duty, CP21/36: A new Consumer Duty: feedback to CP21/13 and further consultation.

https://www.fca.org.uk/publications/consultation-papers/cp21-36-new-consumer-duty-feedback-cp21-13-further-consultation

Gatehouse Bank (2019) https://gatehousebank.com > about-us > csr-outreach-programmes

Gendron Y, Smith-Lacroix J-H (2013), The global financial crisis: Essay on the possibility of substantive change in the discipline of finance, Critical Perspectives on Accounting 10/2013;

GFANZ, (2021a), The Glasgow Financial Alliance for Net Zero, https:/unfccc.int/news/new-financial-alliance-for-net-zero-emissions-launches

Global Alliance for Banking on Values (GABV), https://www.gabv.org/

Golden-Biddle, K. \& Locke, K. (2007). Composing Qualitative Research (2 ${ }^{\text {nd }}$ ed.). Sage Publications.

Gond, J. P., Grubnic, S., Herzig, C., and Moon, J. (2012) Configuring management control systems: Theorizing the integration of strategy and sustainability. Management Accounting Research, 23(3), 205-223.

Gray, R., Javad, M., Power, D.M., and Sinclair, C.D. (2001). Social and environmental disclosure and corporate characteristics: a research note and extension. Journal of Business Finance and Accounting, Vol. 28 Nos 3/4, pp. 327-355.

Gratton, L., and Ghoshal, S. (2002) "Improving the Quality of Conversations" Organizational Dynamics, Winter, 31/3: 209-223

Guardian, October $1^{\text {st }}, 2018$, 'Tesco Bank fined $£ 16.4 \mathrm{~m}$ by watchdog over cyber-attack '

https://www.theguardian.com/business/2018/oct/01/tesco-bank-fined-cyber-attack-fca

Guthrie, J. and Parker L., (1990), “Corporate social disclosure practice” Advances in Public Interest Accounting, Vol. 3, pp. 159-173.

Guthrie J J, Ricceri F, Dumay J (2012), Reflections and projections: A decade of Intellectual Capital Accounting Research, The British Accounting Review 44 (2012) 68-82

Haresnape C (2018), CEO Gatehouse bank, ‘Sustainable solutions', 22nd Oct, 11-12.00 am; Ethical Finance Conference, 22nd-23rd October 2018, Edinburgh,

Harris, L (2002), 'The learning organisation -myth or reality? Examples from the UK retail banking industry' The Learning Organisation, v9 no2, p78-88

Harrison P, (2020, in discussion with Kate Leppard (2020), Head of Client Service, UK Wealth Management, Schroders, 'Schroders' Peter Harrison discusses COVID-19 and beyond': webinar, 21/05/2020, https://www.cazenovecapital.com/uk/financial-adviser/insights/strategy-and-economics/aconversation-with-schroders-ceo-peter-harrison-webinar/

Harrison P, (2019), in discussion with Richard Romer-Lee, Talking with Peter Harrison, Square Mile, 19 $^{\text {th }}$ March 2019 https://www.squaremileresearch.com/Insights/entryid/535/Default

Hart, S. L. (1995). A Natural-Resource-Based View of the Firm. Academy of Management Review, 20(4), 966-1014.

Hart, S. L, Dowell, G. (2011), A Natural-Resource-Based View of the Firm: Fifteen Years After, Journal of Management, Vol. 37 No. 5 , September 2011 1464-1479

Hayhoe K (2021), Saving Us: A Climate Scientist's Case for Hope and Healing in a Divided World, Atria/One Signal Publishers

Heffernan, S. (2005), Modern Banking, John Wiley, Chichester UK

Hendry J., 2013), Ethics and Finance: An Introduction, Cambridge University Press.

Herold D M, Dietrich T, Breibarth T (2021), 'Banking on bullshit: indifferences towards truth in corporate social responsibility', International Journal of Bank Marketing, Vol. 39 No. 4, pp. 618-637. https://doi.org/10.1108/IJBM-04-2020-0207

Hirshleifer, D. (2015). Behavioral finance. Annual Review of Financial Economics, 7, 133-159

Holland, J. (2010), "Banks, knowledge and crisis: a case of knowledge and learning failure", Journal of Financial Regulation and Compliance, Vol.18 No.2, pp 87-105.

Holland, J., Henningsson, J., Johanson, U., Koga, C. \& Sakakibara, S. (2012). Use of IC information in Japanese financial firms. Journal of Intellectual Capital, 13(4), 562-581.

Holland J (2016), A behavioural theory of the fund management firm, European Journal of Finance, Vol 22, Issue 11, pp 1004-1039 
Holland J, (2017a) "The "market for information" - functions, problems and policy proposals", Qualitative Research in Financial Markets, Vol. 9 Issue: 3, pp.263291, https://doi.org/10.1108/QRFM-11-2016-0045

Holland J, (2017b), 'Rethinking Models of Banks and Financial Institutions', Ch 8, Part 3 in; Guthrie, J., Ricceri, F., Dumay, J. and Nielsen, C., Eds. (2017), The Routledge Companion to Intellectual Capital, Routledge, London

Holland, J. B.(2019a), "A new approach to research and theory development for financial firms-Building a "house with windows"", Journal of Financial Regulation and Compliance, Vol. 27 No. 2, pp. 215-242. https://doi.org/10.1108/JFRC-10-2017-0088

Holland J, (2019b), 'Bank top management teams, disclosure, learning, survival and failure -1990-2017', Qualitative Research in Financial Markets, https://doi.org/10.1108/QRFM-03-2018-0031

Holland, J. (2019c), 'Changing financial firms relative to ESG issues'. Chapter 5 in: Arvidsson, S. (ed.) Challenges in Managing Sustainable Business: Reporting, Taxation, Ethics and Governance. Palgrave Macmillan. ISBN 9783319932651 (In Press).

Holland J (2021), 'How can financial firms go green ?', Working paper, The Adam Smith Business School, University of Glasgow, G12 8QQ, UK

IIRC, (2013), Business Model: Background Paper for integrated reporting, London, UK:

IIRC, (2017), International <IR $>$ Framework Implementation Feedback, London, UK, available at; http://integratedreporting.org/wp-content/uploads/2017/10/Framework_feedback_Sum2017.pdf

(IIRC), (2021), The International $<\mathrm{IR}>$ Framework, International Integrated Reporting Council, London, UK. https://integratedreporting.org/wp-content/uploads/2021/01/InternationalIntegratedReportingFramework.pdf

Jizi, M.I., Salama, A., Dixon, R. and Stratling, R. (2013), "Corporate governance and corporate social responsibility disclosure: evidence from the US banking sector", Journal of Business Ethics, Vol. 125 No. 4, pp. 601-615.

Jones A (2021), 'How Covid-19 is impacting the banking workforce', International Banker, June 17, 2021

Kay J, King M, (2020), 'Radical Uncertainty: Decision-making for an unknowable future', The Bridge Street Press, March 2020

Keasey, K. and Hudson, R. (2007), "Finance theory: a house without windows”, Critical Perspectives on Accounting, Vol. 18 No. 8, pp. $932-951$.

Kilic, M., Kuzey, C. and Uyar, A. (2015), “The impact of ownership and board structure on corporate social responsibility in the Turkish banking industry", Corporate Governance: The International Journal of Business in Society, Vol. 15 No. 3, pp. 357-374.

Kinderman, Daniel P., (2018) Corporations and Global Standards of Corporate Social Responsibility (September 28, 2018). Chapter 23 for Andreas Nölke and Christian May (eds) The Handbook of the International Political Economy of the Corporation. Cheltenham: Edward Elgar, 2018 , pp. 365-383.

KPMG (2016), Corporate responsibility reporting in the Banking sector, https://assets.kpmg//content/dam/kpmg/xx/pdf/2016/08/corporate-responsibility-banking-sector.pdf

Knights David , Hugh Willmott (1997), The Hype and Hope of Interdisciplinary Management Studies, March 1997, British Journal of Management 8(1):9 - 22 La Torre M. (2020) Knowledge Management, Risk Management, Knowledge Risk Management: What Is Missing (or Messed) in Financial and Banking Sectors. In: Risk in Banking. Palgrave Pivot, Cham. https://doi.org/10.1007/978-3-030-54498-0_3

Lejarraga, J, Pindard-Lejarraga, M (2020), Bounded Rationality: Cognitive Limitations or Adaptation to the Environment? The Implications of Ecological Rationality for Management Learning, Academy of Management Learning \& Education . Sep2020, Vol. 19 Issue 3, p289-306. 18p.

Laidroo L, Sokolova M, (2015) "International banks' CSR disclosures after the 2008 crisis", Baltic Journal of Management, Vol. 10 Issue: 3 , pp.270-294, https://doi.org/10.1108/BJM-08-2014-0128

Larsen M, Tan S Y, (2015), 'Applying the Integrated Reporting concept of 'capitals' in the banking industry'; Published on behalf of Banking Network August, 2015.

Larsen M (2017), Innovation in banking - are we communicating the value created? , $<\mathrm{IR}>$ Banking Network, March 2017

Larsen , (2021), Ethical Finance Summit (June $\left.9^{\text {th }} 2021\right)$, Edinburgh

Lave, J. and Wenger, E. (1991), Situated Learning: Legitimate Peripheral Participations, Cambridge University Press, Cambridge, MA

Lengnick-Hall, C. A., Beck, T. E., \& Lengnick-Hall, M. L. (2011). Developing a capacity for organizational resilience through strategic human resource management Human Resource Management Review, 21, 243-255.

Lewin, K. (1947). 'Frontiers in group dynamics'. In Cartwright, D. (Ed.), Field Theory in Social Science. London: Social Science Paperbacks

Lewis, M. and Davies, K. T. (1987), Domestic and International Banking, MIT Press, Massachusetts

Lindblom, Charles E. (1959), The science of 'muddling through'. Public Administration Review, 19, pp. 79-88.

Lloyds bank (2009) https://www.lloydsbankinggroup.com/globalassets/documents/our-

group/responsibility/reports/corporate_responsibility_report 2009.pdf

Lock, I., \& Seele, P. (2015). Analyzing Sector-Specific CSR Reporting: Social and Environmental Disclosure to Investors in the Chemicals and Banking and Insurance Industry. Corporate Social Responsibility and Environmental Management,22(2), 113-128.

Luyendijk J., (2016), "Big banks still have a problem with ethics and morality", Guardian Jan 18, available at: https://www.theguardian.com/sustainable-business/2016/jan/18/big-banks-problem-ethics-morality-davos

Matthews A (2018), Director of Ethics and Engagement, Church of England Pensions Board, Panel 5, Investing and engaging to prevent climate change, 22nd Oct,16.20-17.20 pm; Ethical Finance Conference, 22nd-23rd October 2018, Edinburgh,

Mattis, M. (2008). CSR-washing is the new greenwashing. Money Watch, CBS News. https://www.cbsnews.com/news/csr-washing-is-the-newgreenwashing/

Meritum, (2002). Guidelines for managing and reporting on intangibles (Intellectual Capital Report). Tucson, AZ. 
Michelon G, Pilonato S, Ricceri F (2015), CSR reporting practices and the quality of disclosure: An empirical analysis, Critical Perspectives on Accounting 33 (2015) 59-78

Mitleton-Kelly, Eve (2003) Ten principles of complexity and enabling infrastructures. In: Mitleton-Kelly, Eve, (ed.) Complex Systems and Evolutionary Perspectives on Organisations: the Application of Complexity Theory to Organisations. Advanced series in management. Elsevier Science Ltd, Oxford, UK, pp. 3-20. ISBN 9780080439570

Morgan, G. and Smircich, L. (1980), “The case for qualitative research”, Academy of Management Review, Vol. 5 No. 4, pp. 491-500.

Morgan, G. (1986, 1997), Images of Organization, SAGE Publications, Newbury Park, CA.

Mouritsen, J., Bukh, P.N., Larsen, H.T. and Johansen, M.R. (2002), "Developing and managing knowledge through intellectual capital statements", Journal of Intellectual Capital, Vol. 3 No. 1, pp. 10-29.

Mumford, E. A (2000), Socio-Technical Approach to Systems Design. Requirements Eng 5, 125-133.

NatWest (2019), NatWest signed up to PRB Sept 2019 , UNEP FI (September 2019) Principles of Responsible Banking (PRB). UNEP Financial Initiative, https://www.rbs.com/rbs/news/2019/09/rbs-becomes-a-founding-signatory-of-the-principles-for-responsib.html

Norberg, P. (2018), "Bankers bashing back: amoral CSR justifications”, Journal of Business Ethics, Vol. 147 No. 2, pp. 401-418.

O'Donnell, D., Bo Henriksen, L., Voelpel, S.C., "Guest editorial: becoming critical on intellectual capital", Journal of Intellectual Capital, Vol. 7 No. 1, pp. 5-11

OECD, 2016, Green investment banks; http://www.oecd.org/environment/cc/Green-Investment-Banks-POLICY-PERSPECTIVES-web.pdf OECD, 2021, Responsible Business Conduct, http://mneguidelines.oecd.org/

Ortiz-de-Mandojana, N. and Bansal, P. (2016), "The long-term benefits of organizational resilience through sustainable business practices", Strategic Management Journal, Vol. 37, pp. 1615-1631

Owen V (2020) How does an asset manager like Schroders actively influence the companies it invests in? 18 August Elly Irving, Schroders' Head of Engagement, answers questions on why investors engage and how they influence firms' practices. https://www.trustnet.com/news/7465921/how-does-an-asset-manager-like-schroders-actively-influence-the-companies-it-invests-in

Paris (2015),Paris Agreement on Climate Change, UNFCCC, Paris, 12th December 2015.

Partington R (2019), Guardian, 24 th April, 'Ballooning executive pay is at last coming under scrutiny' https://www.theguardian.com/business/2019/apr/24/ballooning-executive-pay-is-at-last-coming-under-scrutiny

Pathan, S. (2009), "Strong boards, CEO power and bank risk-taking”, Journal of Banking \& Finance, Vol. 33 No. 7, pp. 1340-1350.

Paulik, J., Kombo, F. and Kljucnikov, A. (2015), "CSR as a driver of satisfaction and loyalty in commercial banks in the Czech Republic", Journal of International Studies, Vol. 8 No. 3, pp. 112-127.

Pedler M, Burgoyne J, Boydell T, (1997) ; ‘ The learning company : A strategy for sustainable development' ; McGraw Hill, London, $2^{\text {nd }}$ Edition.

Perrini F, Vurro C, (2010), ‘Corporate Sustainability, Intangible Assets Accumulation and Competitive Advantage Constraints', Symphonya, Emerging Issues in Management, n. 2, 2010, pp. 25-38

Pope S and Wæraas A (2016), CSR-Washing is Rare: A Conceptual Framework, Literature Review, and Critique : Journal of Business Ethics, August 2016, Vol. 137, No. 1 (August 2016), pp. 173- 193

Porter, M. (1985). Competitive advantage: Creating and sustaining superior performance. New York, Free Press.

Porter, M., Kramer M., (2011, Jan-Feb). "The Big Idea: Creating Shared Value, Rethinking Capitalism", Harvard Business Review

Porter, M., Kramer M., (2011, January-February). "The Big Idea: Creating Shared Value, Rethinking Capitalism", Harvard Business Review

Poterba James, MIT (2021, Discussion of “How Can Financial Firms Go Green?” by John Holland, 5th August 2021, World Finance Conference - Norway

Power M. (2003), Auditing and the production of legitimacy. Accounting Organizations and Society,;28(4):379-94

Preda, A. (2005), "Legitimacy and status groups in financial markets", The British Journal of sociology, Vol. 56 No. 3, pp. 451-471

PRI (2020), Principles of Responsible Investment, https://www.unpri.org/

PRB (2019), (Principles of Responsible Banking ), UNEP Financial Initiative, 2019, https://www.unepfi.org/banking/bankingprinciples/

PSI (2021), UNEP (2021), Principles for Sustainable Insurance, https://www.unepfi.org/psi/

ProCredit Bank Group (2016), Environmental Management Policy,

https://www.procreditbank.de/images/documents/PCBG_Environmental_Policy.pdf

Puxty, A. G., Willmott, H. C., Cooper, D. J., Lowe, A., "Modes of regulation in advanced capitalism: locating accountancy in four countries", Accounting, Organisations and Society, Vol. 12, No. 3, 1987, p. 273-291.

Raut, R., Cheikhrouhou R R, N. and Kharat, M. (2017), "Sustainability in the banking industry: a strategic multi-criterion analysis", Business Strategy and the Environment, Vol. 26 No. 4, pp. 550-568.

Rawstorne T, (2015), Daily Mail,16 May 2015, Mail Online. https://www.dailymail.co.uk/news/article-3084032/The-self-service-bank-branches-driving-Britain-distraction-Instead-line-counter-staff-customers-facedmaddening-machines.html

RBS (2018), 'Approach To Climate Change', https://www.rbs.com/rbs/sustainability/responsible-business/approach-to-climate-change.html

RBS (2014), Building a truly customer centric bank - Strategy Outline, 27 February 2014

https://investors.rbs.com/ /media/Files/R/RBS-IR/results-center/strategy_slides.pdf 
Rice S (2019), at Ethical Finance Conference, Edinburgh, $8^{\text {th }}$ October, 2019

Rolfe A (2020), Banks suffer post COVID-19 consumer crisis of confidence, Accenture, Dec $8^{\text {th }} 2020$ https://www.paymentscardsandmobile.com/banks-suffer-post-covid-19-consumer-crisis-of-confidence

Rose A : 'Building a purpose-led bank',14Feb 2020, Scottish Financial News https://www.scottishfinancialnews.com/article/alison-rose-building-a-purpose-led-bank

Rose A, CEO of NatWest/RBS, 'Greening the financial system and making green financial products mainstream', City Week $21^{\text {st }}$ Sept $2020,9.25-10.10$ am, $10^{\text {th }}$ Annual International Financial Services Forum https://www.youtube.com/watch?v=k-7fUV8q15A\&feature=youtu.be

Rushe D (2021), Green investing 'is definitely not going to work', says ex-BlackRock executive, Guardian, Tue 30 Mar 2021 https://www.theguardian.com/business/2021/mar/30/tariq-fancy-environmentally-friendly-green-investing

Schein, E.H. (1989). Organizational culture and leadership. San Francisco, CA: Jossey-Bass.

Scholtens B, and van Wensveen D (2003), The theory of financial intermediation: an essay on what it does (not) explain, SUERF - The European Money and Finance Forum, Vienna 2003

Scholtens, B. (2009). Corporate social responsibility in the international banking industry, Journal of Business Ethics, 86, 159-175.

Schroders (2019), 'SustainEx', April 2019.

https://www.schroders.com/en/sysglobalassets/digital/insights/2019/pdfs/sustainability/sustainex/sustainex-short.pdf

Schroders (2020), Schroders' Global Climate Change strategy , https://www.schroders.com/getfunddocument/?oid=1.9.382755

Stones, R. (2005), Structuration Theory, Palgrave, London.

Scott, W.R. 2001. Institutions and Organizations, 2nd edn. Thousand Oaks: Sage.

Shaw G (2019), Which? UK, 'Bank transfer scam victims to get refunds from May 2019' https://www.which.co.uk/news/2019/02/bank-transfer-scam-victims-to-get-refunds-from-may-2019/

Shen, Chung-Hua \& Wu, Meng-Wen \& Chen, Ting-Hsuan \& Fang, Hao, 2016. "To engage or not to engage in corporate social responsibility: Empirical evidence from global banking sector," Economic Modelling, Elsevier, vol. 55(C), pages 207-225.

Shiller R, 2019, Narrative Economics: How Stories Go Viral and Drive Major Economic Events, Princeton University press

Silverman D (1970), The Theory of Organisations: A Sociological Framework, Heinemann.

Silverman, D. (2021). Collecting qualitative data during a pandemic. Communication and Medicine, 17(1), 76-84. https://doi.org/10.1558/cam.19256

Simpson GW, Kohers T. 2002. The link between corporate social and financial performance: Evidence from the banking industry. Journal of Business Ethics 35 (2): 97-109

Statman M (1999), Behaviorial Finance: Past Battles and Future Engagements, Financial Analysts Journal, 55(6):18-27 November 1999.

Statman M (2014), Behavioral finance: Finance with normal people, Borsa_Istanbul Review 14 (2014)

Steer T (2018), 'The Signs Were There - The clues for investors that a company is heading for a fall', Allen \& Unwin, London.

Strauss, A. and Corbin, J. (1998). Basic of qualitative research: Techniques and procedures for developing grounded theory (2nd ed.). Thousand Oaks, CA: Sage Publications.

Streeck W, Schmitter P C, (1985), Community, Market, State-and Associations? The Prospective Contribution of Interest Governance to Social Order, European Sociological Review, Vol. 1, No. 2 (Sep., 1985), pp. 119-138, OUP

Streeck, W., \& Schmitter, P. C. (1985), "Community, Market, State--and Associations?" Chap. 1, pp. 1-29, in Streeck, W., \& Schmitter, P. C., (eds.) Private Interest Government: beyond market and state, (Sage, London, 1985).

Teece, D; Pisano, G; Shuen, A (August 1997). Dynamic Capabilities and Strategic Management ", Strategic Management Journal, 18 (7): $509-533$

Thompson, P., \& Cowton, C. (2004). Bringing the environment into bank lending: implications for environmental reporting, The British Accounting, Review, 36, 197-218.

Torre M., Bernardi C., Guthrie J., and Dumay J., (2018), "Integrated Reporting and integrated thinking: Practical Challenges", in. "Challenges in managing sustainable business- Reporting, Taxation, Ethics and Governance”, Palgrave MacMillan, London

Tran, Y T H, (2014), CSR in Banking sector; A literature review and new research directions

International Journal of Economics, Commerce and Management United Kingdom Vol. II, Issue 11, Nov 2014

http://ijecm.co.uk/wp-content/uploads/2014/11/21112.pdf

Triodos Bank (2019), https://www.triodos.com/about-us

UN (2021), UN Global Compact, https://www.unglobalcompact.org/what-is-gc/mission/principles

UNDP (2016), Sustainable Development Goals, http://www.undp.org/content/undp/en/home/sustainable-development-goals.htm

UNEP Finance Initiative (2015), The Principles for Positive Impact Finance: A Common Framework to Finance The Sustainable Development Goals. http://www.unepfi.org/positive-impact/principles-for-positive-impact-finance/

UNIDO (2019), United Nations Industrial Development Organization, "What is CSR"

https://www.unido.org/our-focus/advancing-economic-competitiveness/competitive-trade-capacities-and-corporate-responsibility/corporate-social-responsibility-market-integration/what-cs

Vaccoro J (2019), Triodos bank, at Ethical Finance, Edinburgh, 8th October, 2019

Van Ast L, 2019, at Ethical Finance, Edinburgh, 8th October, 2019

VRF (2021), (Value Reporting Foundation), Integrated Thinking Principles: Supporting Holistic Decision-Making, http://www.integratedreporting.org/wpcontent/uploads/2021/12/VRF ITP-Main-120721.pdf 
Wiœniewski M (2015), CSR Risk Management, Forum Scientiae Oeconomia Volume 3 (2015) No. 4

Whitley, R. (1999). Divergent capitalisms: The social structuring and change of business systems. Oxford: Oxford University Press.

Wright W, (2018), 'Report: Understanding the gender pay gap in banking and finance', Ecommerce reports, Driving diversity. https://newfinancial.org/report-understanding-the-gender-pay-gap-in-banking-and-finance/

Wu M-W, Shen C-H (2013), Journal of Banking \& Finance, Volume 37, Issue 9, September 2013, Pages 3529-3547

Corporate social responsibility in the banking industry: Motives and financial performance

WWF (2021), Turning Blue Chips Green : A Review of FTSE100 Net Zero Commitment October 2021.

https://www.wwf.org.uk/sites/default/files/2021-10/Net zero scorecard report.pdf

Zack, M.H. (1999). Developing a knowledge strategy. California Management Review, 41(3), 125-145.

Zimmermann (2019), "Same same but different: how and why banks approach sustainability", Sustainability, Vol. 11 No. 8, p. 2267, doi: 10.3390/su11082267 (accessed 10 January 2020). 